Please do not remove this page

RMIT

UNIVERSITY

\title{
Re-examination of convergence hypothesis among Indian states in panel stationarity testing framework with structural breaks
}

Mishra, Ankita; Mishra, Vinod

https://researchrepository.rmit.edu.au/esploro/outputs/9921863087101341/filesAndLinks?institution=61RMIT_INST\&index=null

Mishra, A., \& Mishra, V. (2017). Re-examination of convergence hypothesis among Indian states in panel stationarity testing framework with structural breaks. Applied Economics, 50(3), 268-286.

https://doi.org/10.1080/00036846.2017.1319559

Document Version: Accepted Manuscript

Published Version: https://doi.org/10.1080/00036846.2017.1319559

Repository homepage: https://researchrepository.rmit.edu.au

(C) 2017 Informa UK Limited, trading as Taylor and Francis Group

Downloaded On 2023/04/27 00:31:58 +1000 
Thank you for downloading this document from the RMIT Research Repository.

The RMIT Research Repository is an open access database showcasing the research outputs of RMIT University researchers.

RMIT Research Repository: http://researchbank.rmit.edu.au/

\section{Citation:}

Mishra, A and Mishra, V 2018, 'Re-examination of convergence hypothesis among Indian states in panel stationarity testing framework with structural breaks', Applied Economics, vol. 50, no. 3, pp. 268-286.

See this record in the RMIT Research Repository at:

https://researchbank.rmit.edu.au/view/rmit:48247

Version: Accepted Manuscript

Copyright Statement:

C 2017 Informa UK Limited, trading as Taylor and Francis Group

\section{Link to Published Version:}

https://dx.doi.org/10.1080/00036846.2017.1319559 


\title{
Re-examination of Convergence Hypothesis among Indian States in Panel Stationarity \\ Testing Framework with Structural Breaks ${ }^{+}$
}

\author{
Ankita Mishra \\ School of Economics, Finance and Marketing \\ RMIT University \\ Email: ankita.mishra@,rmit.edu.au
}

$\&$

\author{
Vinod Mishra* \\ Department of Economics \\ Monash University \\ VIC-3800, Australia \\ Email:vinod.mishra@monash.edu \\ Phone: +61399047179
}

\footnotetext{
${ }^{+}$We thank Prof Russell Smyth (Monash university), participants of 10th Annual Conference on Economic Growth and Development (Indian Statistical Institute) and the two anonymous referees for helpful comments on earlier versions of this article. We thank Prof. Josep Lluís Carrion-i-Silvestre (University of Barcelona) for providing the GAUSS codes for estimating the unit root tests proposed in Carrion-i-Silvestre and Sansó (2007) and Bai and Carrion-i-Silvestre (2009). We, alone, are responsible for the views expressed therein and any remaining errors.

${ }^{*}$ Corresponding Author.
} 


\title{
Re-examination of Convergence Hypothesis among Indian States in Panel Stationarity Testing Framework with Structural Breaks
}

\begin{abstract}
This paper examines the conditional income convergence hypothesis for 17 major states in India for the period of 1960 to 2012. Univariate stationarity tests without structural breaks provide evidence against the convergence hypothesis. However, when two or more structural breaks are applied in per capita income series, the incomes of around 11-13 states are found to stochastically converge to the national average. The finding supports that the convergence hypothesis for the panel as a whole after accounting for two data features, cross-sectional dependence and structural breaks in incomes, using a unified panel stationarity testing framework.
\end{abstract}

Keywords: India; panel unit root; structural break; convergence JEL codes: O40, C12 


\section{Introduction}

Economic growth models based on new growth theory envision poor regions catching up with rich regions in terms of income per capita. According to growth models, the payoffs of additional capital or better technology are greater for a poor economy. Hence, poor economies should be able to increase their growth rate at a faster rate than richer economies, enabling them to catch up.

Various studies in the literature have taken an empirical view to determine whether the economies of different groups of countries have actually caught up or converged (Mankiw et al., 1992; Evans, 1996, 1997), and diverse regions (or states) within a single large country have also been considered. These latter studies have primarily focused on the United States (Young et al., 2008; Carlino \& Mills, 1993). The two main techniques used to investigate the convergence hypothesis are cross-sectional growth equation estimates (Barro \& Sala-i-Martin, 1992, 1995; Mankiw et al., 1992) and time series unit root testing (Bernard \& Durlauf, 1995; Carlino \& Mills, 1993; Fleissig \& Strauss, 2001; Strazicich et al., 2004). The convergence hypothesis has been found to hold true for varied samples of industrial countries and their regions in cross-sectional studies, although time series evidence remains ambiguous (Strazicich et al., 2004).

The notion of convergence, defined as inclusive growth, holds a pivotal place in Indian central planning. Even though inter-state variation in growth rates has fallen in India over the years, imbalances in regional growth still remain acute in India. Bandyopadhyay (2011) has argued that some of the richest states in India (e.g. Gujarat and Maharashtra) are akin to middle-income countries, such as Poland and Brazil, in their level of development, whereas the poorest states of Bihar, Uttar Pradesh and Orissa are similar to some of the poorest sub-Saharan countries in Africa.

Various studies have examined the convergence hypothesis for Indian states. The majority of these studies have found little support for absolute convergence ${ }^{1}$ among Indian states. Rather, these studies have found evidence in favour of absolute divergence (Marjit \& Mitra, 1996; Ghosh et al., 1998; Nagaraj et al., 2000; Rao et al., 1999; Dasgupta et al., 2000; Sachs et al., 2002; Trivedi, 2002; Shetty, 2003; Bhattacharya \& Sakthivel, 2004; Baddeley, 2006; Kar \& Sakthivel, 2007; Nayyar, 2008; Ghosh, 2008, 2010, 2012; Kalra \& Sodsriwiboon, 2010). In only a few cases, studies have confirmed absolute convergence, and several other studies have found support for conditional convergence (Dholakia, 1994; Cashin \& Sahay, 1996a, 1996b; Nagaraj et al., 2000; Sachs et al., 2002; Trivedi,

\footnotetext{
${ }^{1}$ The three competing hypotheses on convergence as defined by Galor (1996) are: (1) the absolute convergence hypothesis, where per capita income of countries (or regions) converge to one another in the long term, irrespective of their initial conditions; (2) the conditional convergence hypothesis, where per capita income of countries that are identical in their structural characteristics converge to one another in the long term, irrespective of their initial conditions; and (3) the club convergence hypothesis, where per capita income of countries that are identical in their structural characteristics converge to one another in the long term, provided that their initial conditions are similar.
} 
2002; Baddeley, 2006; Nayyar, 2008; Ghosh, 2008, 2010, 2012; Kalra \& Sodsriwiboon, 2010). Some studies have also examined the club convergence hypothesis ${ }^{2}$ for Indian states and found limited support for it as well (Baddeley et al., 2006, Bandyopadhyay, 2011 and Ghosh et al., 2013).

Most studies that examine the convergence hypothesis in India are based on a cross-sectional growth convergence equation approach ${ }^{3}$ (Bajpai \& Sachs, 1996; Cashin \& Sahay, 1996; Nagaraj et al., 2000; Aiyar, 2001; Trivedi, 2002). Very few studies have followed a stochastic convergence approach. These latter studies have employed different techniques, such as stochastic kernel density in Bandyopadhyay (2011) or nonlinear transition factor models in Ghosh et al. (2013) and PhillipsPerron (PP) (Phillips, 1987; Phillips \& Perron, 1988) unit root test without structural breaks in Ghosh (2012). None of these studies have used panel unit root tests with structural breaks. Many studies have highlighted the shortcoming of such time series approaches. Bandyopadhyay (2011), for example, pointed out that time series approaches that estimate the univariate dynamics of income remain incomplete when describing the dynamics of the entire cross section. Ghosh (2013) has argued that unit root tests employed in stochastic convergence literature are less reliable because they ignore possible structural breaks. Addressing these concerns, this paper employs the latest advances in the time series approach to examine the stochastic income convergence hypothesis ${ }^{4}$ among 17 Indian states for the period 1960 to 2012. This paper finds evidence to support income convergence among Indian states, contrary to earlier studies.

This paper contributes to the literature on income convergence in India in several ways. First, the testing methodology used herein is not prone to rejections of the null hypothesis in the presence of a unit root with break(s). With this approach, the rejection of the null hypothesis (of a unit root) unambiguously implies stationarity in contrast to earlier uses of unit root tests with breaks, in which rejection of the null may indicate a unit root with break(s) rather than a stationary series with break(s). Secondly, this study employs panel versions of unit root tests with structural breaks that can exploit

\footnotetext{
${ }^{2}$ Club convergence entails identifying subsets of states that share the same steady state (or clustering the income data into convergence clubs) and checking whether convergence holds up within these groups (Ghosh et al., 2013). In club convergence models, one state is a leading state, known as the leader. All countries with an initial income gap less than a particular amount (refer to Chatterjee (1992) for details) will eventually catch up with the leader. In the steady state, all these countries will grow at the same rate and constitute an exclusive convergence club.

${ }^{3}$ For details of this approach, refer to Barro and Sala-i-Martin $(1992,1995)$, Sala-i-Martin (1996) and Mankiw et al. (1992).

${ }^{4}$ The notion of stochastic convergence implies that shocks to the income of a country (or a region within a country) relative to the average income of a group of countries (or regions) will be temporary. This entails testing the null hypothesis of a unit root in the log of the ratio of per capita income relative to the average. Failure to reject the null of the unit root suggests incomes are diverging and provides evidence against income convergence. Alternatively, rejection of the null hypothesis of the unit root supports income convergence. Since the test includes a constant term, stochastic convergence implies that incomes converge to a country- or regionspecific compensating differential. Hence, stochastic convergence is consistent with conditional convergence (Strazicich et al., 2004).
} 
both the cross-sectional and time series information available in the data to evaluate the convergence hypothesis, while still allowing for potential structural breaks. Thus, in a situation in which univariate unit root tests (with or without structural breaks) give conflicting results, overall income convergence can still be ascertained. Thirdly, cross-sectional dependence is a potential problem in examining the income convergence hypothesis for states within the same country. For example, cross-sectional dependence may arise due to the presence of economy-wide shocks, which can affect all regions simultaneously. One way to remove cross-sectional dependence is to use relative per capita income per state (i.e. the per capita income of a particular state divided by the average per capita income of a nation). This type of transformation has been used in various previous studies as well to account for cross-sectional dependence in similar or different contexts (Bandyopadhyay, 2011; Meng et al., 2013; Strazicich and List, 2003; Strazicich et al., 2004; Mishra and Smyth, 2014). This transformation has the advantage of removing possible cross-sectional shocks that could have affected all states in the panel. For example, a positive shock to per capita state domestic product (SDP) across all states will increase the average by the same proportion and hence leave the relative per capita GDP series unchanged. This suggests that any structural breaks identified in the transformed series should be state specific. However, this relative measure of per capita income is not sufficient to remove crosssectional dependence. Cross-sectional dependence along with the existence of structural breaks in the panel of states used in this study suggest that the income convergence hypothesis cannot be assessed unless a method is used that simultaneously takes into account these factors. Therefore, Bai and Carrion-i-Silvestre (2009) applied a panel unit root test that can address both possible cross-sectional dependence and structural breaks in a unified framework.

The rest of the paper is organised as follows. Section 2 outlines the econometric methodology. Sections 3 and 4 describe the data and present the results. Section 5 discusses the results, and Section 6 presents the conclusions.

\section{Econometric methodology}

\section{1 Conventional unit root tests}

To start with, this paper employs conventional univariate unit root testing methods without structural breaks as a benchmark. The comparison between these tests and tests with structural breaks helps to identify the extent to which misspecification is due to ignoring structural breaks. ${ }^{5}$

\footnotetext{
${ }^{5}$ All the regression models employed in this paper have both a constant term and linear time trend. With the inclusion of time trend in regression models, the notion of convergence can be interpreted as 'catching up' (definition 1, p. 165 Bernard and Durlauf's (1996)). As Bernard and Durlauf's (1996) pointed out that timeseries tests for economies in a transition state (as is the case here) may erroneously accept the null of 'no convergence' when one economy' per capita output (state in our case) is converging to the per capita output of an economy sitting at a unique steady state from far below. Alternatively stated, time series test may give spurious results if data for the economies in question are driven by transitional dynamics. The inclusion of
} 
The Augmented Dickey-Fuller test (ADF) (Dickey \& Fuller, 1979), the Kwiatkowski-PhillipsSchmidt-Shin (KPSS) stationarity test (Kwiatkowski et al., 1992) and the Lagrange multiplier (LM) unit root test proposed by Schmidt and Phillips (1992) were employed in this study. The null hypothesis for the ADF and LM unit root tests is that the per capita income series of state $i$ contains a unit root. If the null of a unit root is accepted for the per capita income series of state $i$, this implies that shocks to the relative income of state $i$ will be permanent. Hence, the per capita income of state $i$ will diverge from national per capita income. If the null hypothesis of a unit root is rejected, this suggests that shocks to the relative income of state $i$ will be temporary and that, over the long term, the per capita income of state $i$ will converge to the national average. The KPSS test differs from these two tests in its null hypothesis, in which the null hypothesis is indicated by stationarity trend, for example, against the alternative of a unit root. As these tests are well documented in the literature, they are not further discussed. ${ }^{6}$

\subsection{Cross-sectional dependence}

Another issue relevant for this analysis is cross-sectional dependence. As the states lie within a single monetary and fiscal regime and have a high degree of economic and cultural commonalities, their per capita incomes may exhibit cross-sectional dependence. This can create large distortions in univariate and panel unit root tests (Mishra, Sharma and Smyth, 2009). Transforming the series to the natural logarithm of the relative per capita series can remove cross-sectional dependence to an extent.

To test the effectiveness of the transformation to relative per capita income series in removing crosssectional dependence, Pesaran's (2004) cross-sectional dependence (CD) test was conducted before and after transforming income series into relative income series. The null hypothesis in the CD test is that the series are cross-sectionally independent. However, if cross-sectional dependence is found to be present in the data, Pesaran (2004) proposes a cross-sectionally dependent unit root test and its panel counterpart (CIPS), which specifically takes cross-sectional dependence into account. The null hypothesis of the CIPS test is the unit root, after accounting for cross-sectional dependence in the data.

\subsection{Univariate unit root tests with two structural breaks}

Another problem is the possibility of structural breaks in the data series. Many significant events occurred in the Indian economy during the 1960-2012 period, giving rise to the possibility of breaks

intercept (or constant term) in time series testing will account for initial conditions ignoring the transitional part. Therefore, inclusion of both intercept and time trend in the testing procedure will take care of initial conditions as well as transitional dynamics respectively improving the power of the time series tests.

${ }^{6}$ For details, refer to Smyth, Nielsen and Mishra (2009). 
in the trend rate of growth of per capita incomes, and ignoring this possibility could lead to erroneous results.

The LM unit root test of Lee and Strazicich (2003) and the KPSS unit root test of Carrion-i-Silvestre and Sansó (2007) with two endogenous breaks are applied in this study. In the ADF-type endogenous break unit root tests (Zivot \& Andrews, 1992; Lumsdaine \& Papell, 1997), the critical values are derived assuming no break(s) under the null hypothesis; therefore, it is possible to conclude that a data series is trend stationary when in reality it is non-stationary with breaks. This can give rise to a spurious rejection problem (Lee \& Strazicich, 2003). The LM unit root test, on the contrary, is unaffected by breaks under the null hypothesis of a unit root. This paper applies the Model CC specification of Lee and Strazicich (2003) of the LM unit root test which can accommodate two breaks in the intercept and the slope. ${ }^{7}$ This test relies on determining the breaks where the endogenous two-break LM t-test statistic is at a minimum.

The other univariate unit root test used in this paper is the KPSS stationarity test of Carrion-i-Silvestre and Sansó (2007) with two endogenous breaks in the intercept and trend. This test has the null hypothesis of stationarity with structural breaks. For this test, this study used the Bartlett kernel and selected the bandwidth using Andrew's method ${ }^{8}$. The break dates are estimated by minimising the sequence of the sum of squared residuals (SSR) proposed by Kurozumi (2002). This procedure chooses the dates of the breaks from the argument that minimises the sequence of $\operatorname{SSR}\left(T B_{1}, T B_{2}\right)$, where the SSR is obtained from the regression of $y_{t}=f\left(t, T B_{1}, T B_{2}\right)+e_{t}$, such that $f\left(t, T B_{1}, T B_{2}\right)$ denotes the determining specification.

\subsection{Panel unit root tests with structural breaks}

This paper implements the panel KPSS stationarity test with multiple breaks (Carrion-i-Silvestre et al., 2005). This test has the null of stationarity. It allows the most general specification in which each state's relative per capita series can be modelled independently with its own structural breaks caused by state-specific shocks. In addition to the panel test statistic, this test also produces results for individual time series in the panel and allows different series to have a different number of structural breaks. Another salient feature of this test is that it only produces statistically significant breaks. To estimate the break dates, Carrion-i-Silvestre et al. (2005) applied the Bai and Perron (1998) technique. Trimming is necessary when computing estimates of break dates. The trimming region used here is $T[0.1,0.9]$. Once all possible dates are identified, Carrion-i-Silvestre et al. (2005) recommend that the optimal break dates be selected using the modified Schwartz information criterion (SIC) (Liu et

\footnotetext{
${ }^{7}$ For other versions and more technical details of the test, refer to Smyth, Nielsen and Mishra (2009).

${ }^{8}$ While the results as reported in this paper use the Bartlett kernel, they were also estimated using the quadratic kernel. The results were not sensitive to the choice of kernel.
} 
al., 1997) for trending regressors. This method involves sequential computation and the detection of breaks using a pseudo F-type test statistic. The Carrion-i-Silvestre et al. (2005) test allows for a maximum of five structural breaks.

The paper also computes panel LM unit root tests with structural breaks (Im et al., 2005) as a robustness check. Unlike the Carrion-i-Silvestre et al. (2005) test, this test has the null hypothesis of panel unit root.

Finally, to include possible cross-sectional dependence and structural breaks in a unified framework, the Bai and Carrion-i-Silvestre (2009) panel unit root test is conducted. This paper models the crosssectional dependence as a common factors model (e.g. Bai and $\mathrm{Ng}, 2004$; Moon and Perron, 2004). These common factors can distinguish between the co-movements and idiosyncratic shocks that may affect individual time series. Once the time series are filtered for co-movements, the cross-sectional correlation is sufficiently reduced, and one can expect to derive valid panel data statistics.

The Bai and Carrion-i-Silvestre (2009) panel unit root test allows the common factors to be a nonstationary $I(1)$ process, a stationary $I(0)$ process or a combination of both. The advantage of this approach is that it allows common shocks to have different impacts on individuals via heterogeneous factor loadings. As the number and location of structural breaks are unknown and the common and idiosyncratic factors are typically unobservable, this paper uses an iterative estimation procedure for handling the heterogeneous break points in the determining components.

The algorithm of this iterative procedure is detailed in Bai and Carrion-i-Silvestre (2009). After estimating the location of breaks, common factors, factor loadings and the magnitude of changes, modified Sargan-Bhargava (MSB) statistics are calculated for each series. Finally, the individual MSB statistics are pooled to construct the panel MSB. Based on the method used for pooling the individual statistics, Bai and Carrion-i-Silvestre (2009) suggest two types of panel MSB statistics: standardised statistics or a combination of P-values. As suggested in their paper, standardised statistics are best suited for our purposes. Although this paper proposes a relatively complicated model with both cross-sectional dependence and structural breaks modelled simultaneously in one framework, this model is closest to the empirical settings of the current paper.

\section{Data}

The data used are the per capita net state domestic product (NSDP) for 17 major Indian states for the period from 1960 to 2012. Data were collected from the Indiastat database. The NSDPs for the 17 major states were expressed in Indian Rupees (INRs) and provided at different base periods. All the 
series were converted to the common base period of 2004-2005. The 17 major states included in our analysis account for roughly $90 \%$ of India's population and make up around $87 \%$ of India's GDP ${ }^{10}$. The remaining 11 states not included in the analysis were either created very late in the period of analysis (such as Chhattisgarh, Jharkhand and Uttrakhand), were too small and had many missing data points (Goa, Mizoram, Sikkim, Arunanchal Pradesh, Maghalya and Himanchal Pradesh, for example) or had unreliable data points (Jammu, Kashmir and Nagaland, for example). It is a common practise in studies containing state-level analyses of India to only focus on the 15 to 17 major states (refer to Table 3.1 in Ghosh [2013]).

In the sample of states used in this paper, nine states have average annual per capita income below INR 10,000 (US\$ 227), ${ }^{11}$ with Bihar at the bottom of the list. Three states (Haryana, Maharashtra and Punjab) have average annual per capita income above INR 15,000 (US\$ 341), and the remaining five states have average annual per capita income between INR 10,000-15,000 over the entire sample period. Haryana displays the highest fluctuations in income, as measured by standard deviation, and Bihar the lowest ${ }^{12}$. These descriptive statistics are reported in Table 1.

\section{INSERT TABLE 1 HERE}

This paper has taken the relative per capita income measure to examine the convergence hypothesis. For this, the NSDP per capita of state $i$ is converted to its relative NSDP per capita, as follows:

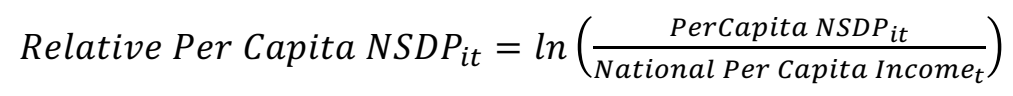

Panel B of Table 1 presents the descriptive statistics of the relative series of per capita income of state $\mathrm{i} /$ national per capita income. In a hypothetical scenario, where the per capita income of a state is exactly equal to the national per capita income, this series will take a value of one, whereas a value smaller than one would mean that the per capita income of that state is less than the national average. A value greater than one would indicate that the per capita income of the state is higher than national per capita income. We note that the per capita income of the poorer states, such as Bihar, Uttar Pradesh and Orissa, are much lower than one, whereas some of the rich states, such as Haryana, Punjab, Gujarat and Maharashtra, are much higher than one.

\footnotetext{
${ }^{9}$ The latest base period used for compiling the net state domestic products.

${ }^{10}$ The Republic of India, as of writing this paper, is made up of 29 states and 6 union territories. However, one state (Telangana) was carved out of Andhra Pradesh in 2014. As the period of analysis for this study concludes in 2012, Telangana is not treated independently but is viewed as part of Andhra Pradesh.

${ }^{11}$ The average annual exchange rate between the Indian rupee and the US dollar during 2004-05 was 1 US\$ = 44 INR.

${ }^{12}$ The associated descriptive statistics table is given in the working paper version of this manuscript.
} 
The entire analysis was conducted on the natural logarithm of this transformed series. The natural logarithm of this relative series means that in the hypothetical scenario where a state's per capita income is exactly equal to the national per capita income, it would take a value of zero. If relative per capita NSDP is found to be stationary, this implies that the per capita income of the state is not drifting away from the national average in the long run. Any state-specific shocks (such as natural disasters, political turmoil or civil unrest) have only a temporary effect, and the per capita series eventually reverts to the national average. If most or all of the per capita income series are found to be stationary around the national average, this would support the income convergence hypothesis, whereas finding a unit root (or non-stationarity) would provide evidence against the convergence hypothesis for Indian states over the long term. This interpretation of convergence is consistent with existing studies that have adopted a time series approach for studying convergence. Some of these studies include Evans and Karras (1996), Evans (1998), Meng et al. (2013) and Mishra and Smyth (2014).

Figure 1 presents the time series plot of the natural logarithm of the relative NSDP series for each state. The horizontal line at zero indicates the hypothetical scenario in which state per capita income is the same as national per capita income (i.e. perfect convergence). A primary examination of the transformed series reveals that each state can be grouped into three distinct categories: states that stayed above the national average throughout the sample period (rich states), states that stayed below the national average (poor states) and states that moved above and below the national average (swing states). The first category comprises Gujarat, Maharashtra and Punjab. The states of Haryana and Kerala are below the national average at the beginning of the sample. However, fairly early in the analysis period, their income surpasses the national average and remains above average for the rest of the analysis period. The second category comprises Uttar Pradesh, Bihar, Orissa and Madhya Pradesh. These states remain below the national average throughout the analysis period. The rest of the states (eight in total) also fall into the category of swing states.

\section{INSERT FIGURE 1 HERE}

\section{Results}

As a benchmarking exercise, the ADF, the Schmidt and Phillips LM unit root test and the KPSS stationarity test without structural breaks were carried out, and results are reported in Table 2. The results for the ADF test suggest that the null of unit root cannot be rejected in any of the transformed series at the traditional levels of significance. In the KPSS test, the null of stationarity is rejected for 11 out of 17 series. The Schmidt and Phillips LM test fails to reject the null of unit root in 12 out of 
17 cases. On the basis of the univariate unit root tests without structural breaks, one can conclude that between zero and six states are converging towards national average per capita income.

\section{INSERT TABLE 2 HERE}

The results for the test of cross-sectional independence are reported in Table 3. The top panel reports the results for the untransformed series. The Pesaran CD statistic is highly significant at all four lags, implying clear rejection of the null of cross-sectional independence. The bottom panel reports CD statistics for the transformed series, wherein the null hypothesis of cross-sectional independence is still rejected. Thus, transforming the series is not enough to remove the cross-sectional dependence in the sample, and there is a need to conduct a CIPS unit root test, which specifically takes into account cross-sectional dependence.

\section{INSERT TABLE 3 HERE}

The results of the Pesaran (2004) CIPS unit root test are reported in Table 4. The results of individual CIPS unit root tests suggest a failure to reject the null of unit root for most states. We note that the null of unit root is rejected at the $5 \%$ level or lower for 6 states at lag 1, for only 2 states at lag 2 and for none at lags 3 and 4 . The results are similar to those obtained using the traditional unit root test: between zero and six states seem to be converging toward national average per capita income. Even though the CIPS test accounts for cross-sectional dependence, these results raise the possibility of a remaining specification bias due to unaccounted structural breaks.

\section{INSERT TABLE 4 HERE}

Table 5 presents the LM unit root test results and the results of the KPSS stationarity test with two endogenous breaks. The Lee and Strazicich (2003) LM unit root test is an LM test with a null hypothesis of unit root in the series. Model CC, the most general specification of the test, was used. In this test, the null hypothesis of a unit root was rejected by looking at the LM parameter. The presence of significant structural breaks was determined by examining the significance of the dummies for breaks in intercept and trend. Table 5 reports the LM test statistics and the break dates, as identified by the test. In terms of the significance of the break dates, the results suggest that, in most of cases, both the dummies (break in intercept and break in trend) were significant or that at least one dummy was significant at each reported break date. After taking into account the occurrence of structural breaks in the series, the null of a unit root in the relative per capita NSDP series was rejected for 11 states (64.8\% of the sample) at the 5\% level of significance or lower and for 13 states 
(76.5\% of the sample) at the $10 \%$ level or higher. Comparing these results with those reported in Column 3 of Table 2, the number of states for which the null of unit root can be rejected increases dramatically when structural breaks were excluded from the data (for 13 out of 17 states in comparison with 5 out of 17$)$.

The second test is the Silvestre and Sanso (2007) KPSS test with two structural breaks, which has a null hypothesis of stationarity. This test uses the Bayesian information criterion (BIC) to select the two significant breaks over the entire set of break-point combinations. The results of this test can be compared with the KPSS test results reported in Table 1, Column 2. The KPSS test uses the same methodology but does not allow for structural breaks in the data. The KPSS test with structural breaks fails to reject the null hypothesis of stationarity for 13 states ( $76.5 \%$ of the sample) at the $5 \%$ level and for 12 states ( $70.5 \%$ of the sample) at the $10 \%$ level or higher.

\section{INSERT TABLE 5 HERE}

The results of individual states for the Carrion-i-Silvestre et al. (2005) KPSS unit root test are reported in Table 6. This test was conducted allowing a maximum of five structural breaks in the intercept and trend of each state's series. However, not every state had five significant structural breaks in the relative per capita NSDP series. Table 6 reports only the significant structural breaks. Even after accounting for up to five structural breaks, the null of stationarity is still found to be rejected in five out of seventeen states.

\section{INSERT TABLE 6 HERE}

In the next step, the stationarity of the overall panel was assessed. Table 7 reports the panel unit root test results for the Hadri (2000) test (without structural breaks), the Carrion-i-Silvestre et al. (2005) test (with a maximum of five structural breaks), the Im et al. (2005) LM unit root test (with zero, one and two structural breaks) and the Pesaran (2004) CIPS test. The Hadri (2000) and Carrion-i-Silvestre et al. (2005) tests are reported with two alternative assumptions: namely, that the long-term variance was homogeneous or was heterogeneous. The null hypothesis of stationarity was not rejected in any of the cases. This result is robust with regard to the alternative assumptions about the variance and the presence/number of structural breaks in the data. These results were confirmed by the panel LM unit root test (Im et al., 2005), reported in Panel C of Table 7. The null hypothesis in this case is a unit root; the test was conducted with alternate specifications of zero, one and two structural breaks in the individual data series. The null hypothesis of unit root was rejected at traditional levels of significance 
in all the specifications. The results of the Pesaran (2004) CIPS tests remain inconclusive with regard to the convergence hypothesis at the overall panel level. The null hypothesis of a unit root was rejected for lags 1 and 2 but was accepted for the lags 3 and 4 at a $5 \%$ level of significance.

An overall view of the results obtained so far suggests the tests with structural breaks (that ignore cross-sectional dependence) show evidence for convergence, whereas the tests that account for crosssectional dependence (but ignore structural breaks) fail to find evidence in support of convergence. To resolve this apparent contradiction, the Bai and Carrion-i-Silvestere (2009) test was used, which simultaneously takes into account possible cross-sectional dependence and multiple endogenous structural breaks. Panel D of Table 7 reports the results of the Bai and Carrion-i-Silvestre (2009) test for the overall panel. All three test statistics reject the null of unit root, suggesting income convergence among Indian states, after controlling for both cross-sectional dependence and structural breaks.

\section{INSERT TABLE 7 HERE}

\section{Discussion}

The results of this study are discussed along two lines. First, evidence for and against income convergence among Indian states is considered. Second, the dates of the structural breaks identified by the tests are addressed in addition to whether these dates actually correspond with major events affecting the Indian economy.

\subsection{Evidence for convergence}

The results of the unit root tests without structural breaks suggest that out of 17 states, anywhere between zero to six states are converging toward the national average, while the rest are diverging. These results are in line with the findings of Ghosh (2013) and Bandyopadhyay \& Lusksic (2015) who applied unit root tests without structural breaks to examine stochastic convergence. ${ }^{13}$ Ghosh (2013) found convergence for five states while Bandyopadhyay \& Lusksic (2015) found four states to be converging in their sample of 15 states. As previously noted, standard unit root tests are less reliable and have low power due to structural breaks that are unaccounted for in the series. Therefore, in allowing for the possibility of structural breaks in the series, we found greater evidence in favour convergence. The same unit root tests (i.e. KPSS and LM tests) give a non-stationary result for most of the series when structural breaks are not included (Table 3) and detect stationarity (for most of the

\footnotetext{
${ }^{13}$ The study by Ghosh (2013) uses Phillips - Perron (PP) unit root test and Bandyopadhyay \& Lusksic (2015) apply ADF, DF-GLS and KPSS tests without structural breaks.
} 
series) when two structural breaks are taken into account (Table 5). The states which do not conform to the convergence hypothesis also vary depending on the unit root test used. The fact that the stationarity hypothesis is rejected for a few states in each test is probably due to the way a particular test models the data generating process.

The results for the individual states in the panel KPSS test (as reported in Table 6) were expected to suffer the least from any possible misspecification bias in the structural breaks, as the possibility of ignoring structural breaks is minimised by allowing five breaks. If anything, there is a possibility of over-fitting the data by allowing too many structural breaks, which would bias the results in favour of convergence. However, this test does not provide stronger evidence for the convergence hypothesis than the tests with two structural breaks and suggests that five states are not converging toward the national average.

In summary, three tests of stationarity that do not allow for structural breaks in the series (ADF test, KPSS test and Schmidt and Phillips unit root test; presented in Table 2) and three tests that allow for structural breaks (Lee and Strazicich [2003] LM unit root test, Carrion-i-Silvestere and Sansó [2007] KPSS unit root test and results for individual states following the Carrion-i-Silvestere et al. [2005] panel unit root test; presented in Tables 5 and 6) were applied. The following rule of thumb was used to assess the overall results for each category: 'If two out of three tests in a particular category suggest stationarity, the series should be categorised as stationary. Otherwise, it is non-stationary'.

Based on this rule of thumb, all states except for Gujarat, Kerala, Rajasthan and West Bengal are nonstationary when structural breaks are not allowed, whereas only the states of Assam and Uttar Pradesh are found to be non-stationary when two or more structural breaks are allowed in the series. To decide between the conflicting stationarity and non-stationarity results, the results obtained from the model with structural breaks are taken as the final result. Tests that allow for structural breaks assumed more parameters in the data generating process and hence better fit the data. Also, given the time series of the last five decades, it seemed natural to rely on the model with structural breaks. Using this decision rule, only the states of Assam and Uttar Pradesh are found to be non-stationary, i.e. do not conform to the convergence hypothesis.

The different versions of the panel unit root tests suggest convergence in per capita incomes. In particular, the results suggest that majority of the states (11-13 in a panel of 17 states) are stochastically converging despite strong differences in the per capita incomes of states. We looked at several other studies to seek potential reasons behind this finding that would support convergence for Indian states. Bandyopadhyay \& Lusksic (2015) found that shocks to the relative incomes are not permanent for the majority of Indian states and that states exhibit a tendency of mean reversion. This 
holds true even for the very poor states for which the effect of shock dissipates for the majority of them within ten years. Ghosh (2013) noted that inter-state variation in physical and social infrastructure has declined though marginally over the years. This can be one of the possible reasons of ensuing convergence for Indian states, as a large number of studies in the literature have found strong links between infrastructure and economic development of the region (such as Bandyopadhyay [2011] and Ghosh [2013]). Besides, the Finance Commission and Planning Commission took several steps to promote regional equality through the intergovernmental transfer of resources (for details, refer to Ghosh [2013] and Rao et al. [2008]).

\subsection{Structural breaks}

The presence of structural breaks has significant implications for our findings. As pointed out by Strazicich et al. (2004), state-specific conditioning variables, such as physical infrastructure/investment expenditure (as measured by irrigation, electrification and railway trackbuilding expenditure in Bandyopadhyay [2011] or Baddeley et al. [2006]), or social infrastructure (defined as human capital in Lahiri et al. [2009]) can be permanently altered following a major shock, making permanent changes to the time path of relative income. In next few paragraphs, the probable causes of these structural breaks are explored. However, these causes can only be considered as probable events relating to breaks and not as evidence of a statistical association with these proposed events or with the time periods of structural breaks. To establish any causal relationship between political, economic and environmental events and a statistically significant break in income is beyond the scope of present study but would be interesting to explore in further research.

For the majority of states, with the exception of Bihar, Gujarat and Tripura, the first and second structural breaks in relative income occurred during the period from 1966 to 1979. India experienced three economic crises during the period, one in 1965-66, a second in 1973-74 and a third in 1979-80 (the period when a second structural break was encountered in most states). All three crises were predominantly balance-of-payment crises caused by a shortage of food crops, which were triggered by droughts and further aggravated by external factors such as wars (with Pakistan in 1965 and 1971) and the international oil crises of 1973 and 1979.

Many states experienced a structural break in the mid to late 1980s. These include Andhra Pradesh (1986), Assam (1984), Bihar (1983-84), Gujarat (1984), Kerala, Madhya Pradesh, Manipur, Tripura and West-Bengal in the 1985-87 period. This period was also marked by several significant political and economic incidents in India. The Indian economy witnessed a turnaround and experienced high growth in the 1980s. This period of development was also characterised by an unsustainable level of government spending, resulting in mounting internal and external debt, that along with expenditure on 
subsidies gave rise to a severe balance-of-payments crisis in India in 1991. On the socio-political front as well, many dramatic changes occurred that may have had varying levels of instantaneous or delayed impact on different states. In 1984, after the assassination of the then Prime Minister, Indira Gandhi, communal riots broke out in New Delhi and in most of northern India, which led to the massacre of around 5,000 citizens of the Sikh faith in Delhi, Kanpur, and other cities. The same year, 1984, also witnessed the world's worst industrial disaster in terms of human lives affected. On December 3, 1984, in Bhopal, the capital city of the central state of Madhya Pradesh, a chemicals manufacturing company (Union Carbide Corporation) released methyl isocyanate (MIC) into the atmosphere above Bhopal. The leak was due to employer negligence and poor plant maintenance. Officially, the state government placed the death toll at around 4,000; however, unofficial estimates have calculated that 20,000 people were killed and over 500,000 injured. The insurgency in the state of Jammu and Kashmir (not included in this analysis) took a difficult turn in 1989 with the exodus of the Kashmiri Pandits (members of a minority Hindu community in the Kashmir valley) and the targeted killing of key community figures. In a relatively short space of time, close to 75,000 Kashmiri Pandit families were forced to flee Kashmir and to seek refuge in other north Indian states. This had considerable impact on the resources and socio-political dynamics of many neighbouring states.

With the exception of Haryana, Madhya Pradesh, Orissa and Tamil Nadu, all states experienced a structural break at some point between 1991 and 1995. Balance-of-payments problems, which started in 1985, continued to be experienced throughout the 1990s. The Iraqi invasion of Kuwait in August 1990 resulted in a sharp increase in the international price of oil, further aggravating the problem, and, by the end of 1990, the Indian economy witnessed a very acute macroeconomic crisis. The government was close to default. The central bank had been refused new credit, and foreign exchange reserves had been reduced to such a point that India could barely finance three weeks' worth of imports. After securing a loan of US\$ 2.2 billion from the IMF (pledging 67 tons of India's gold reserves as collateral), the Indian government initiated a major programme of structural and economic reforms in 1991, bringing about significant policy changes in the external, financial and industrial sectors.

On the political front, ex-prime minister Rajiv Gandhi was assassinated in May 1991 by the Liberation Tigers of Tamil Elam (LTTE), a militant organisation from Sri Lanka. The Indian economy experienced a period of political uncertainty from 1996 to 1999, with three general elections in three years. India also faced a brief period of war with Pakistan in 1999, known as the Kargil War, and short-lived economic sanctions by the United States as a fall out from nuclear tests in 1998. 
In addition to the national events described above, many state-specific events/developments took place during the evaluated period. These can be used to explain the existence of structural breaks in the income series of a particular state that do not match any national event. Table 8 lists the statespecific events that occurred around the break dates.

\section{INSERT TABLE 8 HERE}

\subsubsection{Case study of Uttar Pradesh and Assam}

As noted earlier, for two states, Uttar Pradesh and Assam, convergence to the national average did not hold true in the majority of the tests. A critical analysis of the events in these states is conducted at following in order to discover the reasons behind non-convergence in these states.

Panel B of Figure 1 depicts the breaks in the relative per capita series for Uttar Pradesh. The first structural break in the series seems to be corresponding with the economic crisis of 1965-66 or the India-Pakistan war of 1965. The second structural break, which occurs in either 1971 or 1975, seems to broadly correspond with either the third India-Pakistan war of 1971 or the state of emergency declared by Indira Gandhi's government ${ }^{14}$ in 1975 . However, the reasons for the third structural break in Uttar Pradesh (1990-91) correspond with factors internal to the state rather than national ones. The average per capita income in India increased around 5.5 times in the 16-year period between 1991 and 2007 but for Uttar Pradesh increased only 3.5 times. In relative per capita income terms, Uttar Pradesh became poorer compared with the rest of India, as the relative per capita SDP of Uttar Pradesh has fallen from 77\% in 1991 to $50 \%$ of national per capita SDP in 2007.

The most probable causes for this decline are the political uncertainty and religious unrest prevailing in Uttar Pradesh. In the 16-year period, beginning with the government led by Mualayam Singh in December 1989 through the start of the government led by Mayawati in May 2007, the state witnessed 14 changes of government (accompanied by extended periods of presidential rule), with no chief minister completing his/her full term. There was also religious unrest, and several communal riots broke out during the period. The demolition of a disputed mosque-like structure in Ayodhaya (a city in the Faizabad district of Uttar Pradesh) in 1992 led to the outbreak of Hindu-Muslim riots in Uttar Pradesh and in many other parts of India and resulted in an estimated death toll of more than 2,000 people. Another structural break in Uttar Pradesh's data series occurred in 2007 (at the same

\footnotetext{
${ }^{14}$ The central government, led by Indira Gandhi, ordered the arrest of more than 1,000 key political opponents in 1975 and declared a state of emergency that curbed the power of the press, reduced civil liberties to minimum and suspended elections. The emergency lasted for a 21-month period from June 1975 to March 1977 during which most of Gandhi's political opponents were in prison. This period also witnessed other atrocities, most prominent of which was a forced mass-sterilisation campaign spearheaded by Sanjay Gandhi, the Prime Minister's son. The Emergency is one of the most controversial periods of independent India's history.
} 
time as the Mayawati government was elected and completed the full term). However, the post-2007 sample is too small to be conclusive about the trend in the relative per capita income series following that year.

Meanwhile, the relative per capita SDP of Assam and the estimated structural breaks are presented in Figure 1 (Panel A). Assam is situated in the north-eastern region of India. Assam is rich in natural resources and one of the largest tea-growing regions in the world. Although well-endowed with natural resources, Assam's growth rate has not kept pace with the rest of India. Assam started with per capita income above the national average in the 1960s and remained close to the national average until the first break in income, which occurred somewhere around the mid to late 1970s. The per capita income of Assam was 1.04 of the national average in 1960 yet had fallen to 0.78 of the national average in 1979. This corresponded with the period when the Assam Movement (1979) started to take action against undocumented immigrants. The period ended with the signing of the Assam Accord in 1985 when Asom Gana Parishad (AGP), the party formed by the leaders of the movement, came to power in the state. The second break in Assam's relative per capita income occurred at about this point. Some improvement in the growth rate of Assam's economy was observed during 1985-1990, with average per capita income rising marginally above the national average until the third break in relative per capita income, which took place in the early 1990s. Since this period, the relative per capita income of Assam continues to decline and be below the national average. The main reason for this is the deteriorating law and order situation as a result of indirect support given by the AGP to ULFA (United Liberation Front of Assam) terrorist activities. ULFA, formed in 1979, was the first major insurgent organisation in Assam. Its influence on state politics gradually increased, leading to the collapse of the government in 1990. Presidential rule was imposed from November 1990 to June 1991. Subsequently, the army was deployed in Assam, and ULFA was banned by the Government of India. Militant activity still continues in the state. However, in recent years, the government is making some headway through counter-insurgency offensives and peace efforts. ${ }^{15}$

\section{INSERT FIGURE 2 HERE}

\section{Conclusion}

Using the latest advances in time series techniques, this paper examines the conditional income convergence hypothesis for 17 Indian states from 1960 to 2012. Although the results suggest that unit root tests without structural breaks do not support the income convergence hypothesis for Indian states, tests that include structural breaks provide significant evidence in support of conditional income convergence. Since the panel of states exhibited cross-sectional dependence with respect to

\footnotetext{
${ }^{15}$ For further details, refer to the report on the insurgency and peace efforts in Assam by the Centre for Development and Peace Studies (available at http://cdpsindia.org/assam insurgency.asp).
} 
structural breaks, a testing procedure that simultaneously took these into account was employed. This test provided evidence in support of the conditional income convergence hypothesis for our panel of states. When considered individually, not all states included in the panel are found to be converging. Around 11-13 states (depending on the testing methodology) were found to share a common, steady path with the average national income.

\section{References}

Aiyar, S. (2001). Growth theory and convergence across Indian states: a panel study. India at Crossroads: Sustaining Growth and Reducing Poverty. International Monetary Fund, Washington, 143-169.

Baddeley, M., McNay, K., \& Cassen, R. (2006). Divergence in India: Income differentials at the state level, 1970-97. Journal of Development Studies, 42(6), 1000-1022. doi:10.1080/00220380600774814

Bai, J., \& Carrion-I-Silvestre, J. L. (2009). Structural changes, common stochastic trends, and unit roots in panel data. Review of Economic Studies, 76(2), 471-501. doi:10.1111/j.1467937X.2008.00530.x

Bai, J., \& Ng, S. (2004). A panic attack on unit roots and cointegration. Econometrica, 72(4), 11271177. doi:10.1111/j.1468-0262.2004.00528.x

Bai, J., \& Perron, P. (1998). Estimating and testing linear models with multiple structural changes. Econometrica, 47-78.

Bajpai, N., \& Sachs, J. D. (1999). The progress of policy reforms and variations in performance at the sub-national level in India (HIID Development Discussion Paper No. 730). Cambridge, MA: Harvard Institute for International Development, Harvard University.

Bandyopadhyay, S. (2011). Rich states, poor states: Convergence and polarisation in India. Scottish Journal of Political Economy, 58(3), 414-436. doi:10.1111/j.1467-9485.2011.00553.x

Barro, R. J., \& Sala-i-Martin, X. (1992). Convergence. Journal of Political Economy, 100(2), 223. doi:10.1086/261816

Barro, R., \& Martin, S. (1995). Economic growth. Boston, MA. 
Bernard, A. B., \& Durlauf, S. N. (1995). Convergence in international output. Journal of Applied Econometrics, 10, 97-108. doi:10.1002/jae.3950100202

Bernard, A. B., \& Durlauf, S. N. (1996). Interpreting tests of the convergence hypothesis. Journal of Econometrics 71(1-2), 161-173

Bhattacharya, B. B., \& Sakthivel, S. (2004). Regional growth and disparity in India: Comparison of pre- and post-reform decades. Economic and Political Weekly, 39(10), 1071-1077.

Carlino, G. A., \& Mills, L. O. (1993). Are U.S. regional incomes converging? Journal of Monetary Economics, 32(2), 335-346. doi:10.1016/0304-3932(93)90009-5

Carrion-I-Silvester, J. L., Barrio-Castro, T. Del, \& Lopez-Bazo, E. (2005). Breaking the panels : An application to the GDP per capita. Econometrics Journal, 8, 159-175. doi:10.1111/j.1368423X.2005.00158.x

Carrion-i-Silvestre, J. L., \& Sansó, A. (2007). The KPSS test with two structural breaks. Spanish Economic Review, 9(2), 105-127.

Cashin, P., \& Sahay, R. (1996a). Internal migration, centre-state grants and economic growth in the states of India. IMF Staff Papers, 43(1), 123-171.

Cashin, P., \& Sahay, R. (1996b). Regional economic growth and convergence in India. Finance and Development, 33(1), 49-52.

Chatterjee, M. (1992). Convergence clubs and endogenous growth. Oxford Review of Economic Policy, 8(4), 57-69. Retrieved from http://www.jstor.org/stable/23606277

Dasgupta, D., Maiti, P., Mukherjee, R., Sarkar, S., \& Chakrabarti, S. (2000). Growth and interstate disparities in India. Economic and Political Weekly, 35(27), 2413-2422

Dholakia, R. H. (1994). Spatial dimensions of accelerations of economic growth in India. Economic and Political Weekly, 29(35), 2303-2309.

Dickey, D. A., \& Fuller, W. A. (1979). Distribution of the estimators for autoregressive time series with a unit root. Journal of the American Statistical Association, 74, 427-431. doi:10.2307/2286348 
Evans, P. (1996). Using cross-country variances to evaluate growth theories. Journal of Economic Dynamics and Control, 20(6), 1027-1049.

Evans, P. (1997). How fast do economics converge? Review of Economics and Statistics, 79(2), 219 225.

Evans, P. (1998). Using Panel Data to Evaluate Growth Theories. International Economic Review, 39(2), 295-305.

Evans, P., \& Karras, G. (1996). Convergence revisited. Journal of Monetary Economics, 37, 249-265.

Fleissig, A., \& Strauss, J. (2001). Panel unit-root tests of OECD stochastic convergence. Review of International Economics, 9(1), 153-162.

Galor, O. (1996). Convergence? Inferences from theoretical models. The Economic Journal, 106(437), 1056-1069. Retrieved from http://www.jstor.org/stable/2235378

Ghosh, M. (2008). Economic reforms, growth and regional divergence in India. Margin: The Journal of Applied Economic Research, 2(3), 265-285.

Ghosh, M. (2010). Economic policy reforms and regional inequality in India. Journal of Income and Wealth, 32(2), 71-88.

Ghosh, M. (2012). Regional economic growth and inequality in India during the pre- and post-reform periods. Oxford Development Studies, 40(2), 190-212.

Ghosh, M. (2013). Regional Economic Growth and Inequality. In Liberalization, Growth and Regional Disparities in India, India Studies in Business and Economics series (pp. 17-45). Springer India. doi:10.1007/978-81-322-0981-2_3

Ghosh, B., \& De, P. (1998). Role of infrastructure in regional development: A study of India over the plan period. Economic and Political Weekly, 33(47-48), 3039-3048

Ghosh, M., Ghoshray, A., \& Malki, I. (2013). Regional divergence and club convergence in India. Economic Modelling, 30, 733-742. doi:10.1016/j.econmod.2012.10.008

Hadri, K. (2000). Testing for stationarity in heterogeneous panel data. The Econometrics Journal, $3(2), 148-161$.

Hayashi, F. (2000) Econometrics, Princeton University Press, Princeton. 
Im, K., Lee, J., \& Tieslau, M. (2005). Panel LM unit-root tests with level shifts. Oxford Bulletin of Economics and Statistics, 67(3), 393-419.

Kalra, S., \& Sodsriwiboon, S. (2010). Growth convergence and spillovers among Indian states: What matters? What does not? (IMF Working Paper No. WP/10/96). Washington, DC: International Monetary Fund.

Kar, S., \& Sakthivel, S. (2007). Reforms and regional inequality in India. Economic and Political Weekly, 42(47), 69-77

Kurozumi, E. (2002). Testing for stationarity with a break. Journal of Econometrics, 108, 63-99. doi:10.1016/S0304-4076(01)00106-3

Kwiatkowski, D., Phillips, P. C. B., Schmidt, P., \& Shin, Y. (1992). Testing the null hypothesis of stationarity against the alternative of a unit root: How sure are we that economic time series have a unit root? Journal of Econometrics, 54(1), 159-178.

Lahiri, A. \&Yi, K.-M. (2009). A tale of two states: Maharashtra and West Bengal. Review of Economic Dynamics, 12 (3), 523-542.

Lee, J., \& Strazicich, M. C. (2003). Minimum Lagrange multiplier unit root test with two structural breaks. Review of Economics and Statistics, 85(4), 1082-1089.

Liu, J., Wu, S., \& Zidek, J. V. (1997). On segmented multivariate regression. Statistica Sinica, 7(2), 497-525.

Lumsdaine, R. L., \& Papell, D. H. (1997). Multiple trend breaks and the unit-root hypothesis. Review of Economics and Statistics, 79, 212-218. doi:10.1162/003465397556791

Mankiw, N., Romer, D., \& Weil, D. (1992). A contribution to the empirics of economic growth. Quarterly Journal of Economics. Retrieved from http://www.nber.org/papers/w3541

Maddala, G. S. and S. Wu (1999). A comparative study of unit root tests with panel data and a new simple test. Oxford Bulletin of Economics and Statistics Special issue 61, 631-52.

Marjit, S., \& Mitra, S. (1996). Convergence in regional growth rates: Indian research agenda. Economic and Political Weekly, 31(33), 2239-2242

Meng, M., Payne, J. E., \& Lee, J. (2013). Convergence in per capita energy use among OECD countries. Energy Economics, 36, 536-545. doi:10.1016/j.eneco.2012.11.002 
Mishra, V., Sharma, S. \& Smyth, R. (2009). Are shocks to real output permanent or transitory? Evidence from a panel of Pacific island countries. Pacific Economic Bulletin, 24(1), 65-82

Mishra, V., \& Smyth, R. (2014). Convergence in energy consumption per capita among ASEAN countries. Energy Policy, 73, 180-185. doi:10.1016/j.enpol.2014.06.006

Moon, H. R., \& Perron, B. (2004). Testing for a unit root in panels with dynamic factors. Journal of Econometrics, 122(1), 81-126. doi:10.1016/j.jeconom.2003.10.020

Nagaraj, R., Varoudakis, A., \& Veganzones, M. A. (2000). Long-run growth trends and convergence across Indian states. Journal of International Development, 12, 45-70. Retrieved from http://ovidsp.ovid.com/ovidweb.cgi?T $=J S \& C S C=Y \& N E W S=N \& P A G E=$ fulltext\&D=econ\&AN $\underline{=0609199}$

Nayyar, G. (2008). Economic growth and regional inequality in India. Economic and Political Weekly, 43(6), 58-67.

Perron, P. (1989). The great crash, the oil price shock and the unit root hypothesis, Econometrica, 57, $1361-1401$.

Pesaran, M. H. (2004). General diagnostic tests for cross section dependence in panels. CESifo working paper series.

Phillips, P. C. B. (1987). Time series regression with unit roots. Econometrica, 55(2), 277-302.

Phillips, P. C. B., \& Perron, P. (1988). Testing for a unit root in time series regression. Biometrika, 75(2), 335-346.

Rao, M. G., Shand, R. T., \& Kalirajan, K. P. (1999). Convergence of incomes across Indian states: A divergent view. Economic and Political Weekly, 34(13), 769-778

Sachs, J. D., Bajpai, N., \& Ramiah, A. (2002). Understanding regional economic growth in India (CID Working Paper No. 88). Cambridge, MA: Centre for International Development, Harvard University

Sala-i-Martin, X. X. (1996). The classical approach to convergence analysis. The Economic Journal, 106, 1019-1036. doi:10.2307/2235375

Schmidt, P., \& Phillips, P. C. B. (1992). LM tests for a unit root in the presence of deterministic trends. Oxford Bulletin of Economics and Statistics, 54(3), 257-287. 
Shetty, S. L. (2003). Growth of SDP and structural changes in state economies: Interstate comparison. Economic and Political Weekly, 38(49), 5189-5200

Smyth, R., Nielsen, I., \& Mishra, V. (2009). “I”ve been to Bali too' (and I will be going back): are terrorist shocks to Bali's tourist arrivals permanent or transitory? Applied Economics, 41(11), 1367-1378. doi:10.1080/00036840601019356

Strazicich, M. C., Lee, J., \& Day, E. (2004). Are incomes converging among OECD countries? Time series evidence with two structural breaks. Journal of Macroeconomics, 26(1), 131-145. doi:10.1016/j.jmacro.2002.11.001

Strazicich, M. C., \& List, J. A. (2003). Are CO2 emission levels converging among industrial countries? Environmental and Resource Economics, 24(3), 263-271. doi:10.1023/A:1022910701857

Trivedi, K. (2002). Regional convergence and catch-up in India between 1960 and 1992 (Working Paper, No. 2003-W01). Oxford: Nuffield College, University of Oxford.

Young, A. T., Higgins, M. J., \& Data, E. U. S. C. (2008). Sigma convergence versus beta convergence: Money, Credit and Banking, 40(5).

Zivot, E., \& Andrews, D. W. K. (1992). Further Evidence on the Great Crash, the Oil-Price Shock, and the Unit-Root Hypothesis. Journal of Business \& Economic Statistics, 10. doi:10.1198/073500102753410372 


\section{$\underline{\text { Tables and Figures }}$}

Table 1: Descriptive statistics of per capita Income for the sample period $(1960$ - 2012) for 17 major Indian states

\begin{tabular}{|c|c|c|c|c|c|c|}
\hline Series & Observations & Mean & Std. Dev. & Min. & Max. & Skewness \\
\hline \multicolumn{7}{|c|}{ Panel A: SDP per capita (in Indian Rupees) } \\
\hline Andhra Pradesh & 53 & 12552 & 19108 & 316 & 78958 & 2.01 \\
\hline Assam & 53 & 7959 & 9959 & 395 & 40475 & 1.65 \\
\hline Bihar & 53 & 4449 & 5864 & 245 & 27202 & 2.14 \\
\hline Gujarat & 53 & 16166 & 24096 & 436 & 104261 & 2.06 \\
\hline Haryana & 53 & 18807 & 28490 & 382 & 119158 & 2.05 \\
\hline Karnataka & 53 & 13120 & 18853 & 373 & 76578 & 1.85 \\
\hline Kerala & 53 & 14801 & 21496 & 373 & 88527 & 1.86 \\
\hline Madhya Pradesh & 53 & 8036 & 10325 & 338 & 44989 & 1.80 \\
\hline Maharashtra & 53 & 17821 & 25621 & 463 & 103991 & 1.86 \\
\hline Manipur & 53 & 8261 & 9726 & 204 & 36937 & 1.31 \\
\hline Orissa & 53 & 8438 & 11883 & 275 & 49241 & 1.89 \\
\hline Punjab & 53 & 16518 & 21454 & 407 & 84526 & 1.62 \\
\hline Rajasthan & 53 & 9812 & 13606 & 388 & 59097 & 2.01 \\
\hline Tamil Nadu & 53 & 15464 & 23571 & 430 & 98628 & 2.05 \\
\hline Tripura & 53 & 10568 & 14780 & 369 & 60963 & 1.79 \\
\hline Uttar Pradesh & 53 & 6604 & 8193 & 307 & 33616 & 1.65 \\
\hline West Bengal & 53 & 10714 & 14659 & 452 & 61352 & 1.83 \\
\hline \multicolumn{7}{|c|}{$\begin{array}{l}\text { Panel B: SDP per capita as a fraction of National GDP per capita }=S D P \text { per capita in state } \mathrm{i} / \text { National } \\
\text { GDP per capita }\end{array}$} \\
\hline Andhra Pradesh & 53 & 0.94 & 0.11 & 0.78 & 1.16 & 0.60 \\
\hline Assam & 53 & 0.83 & 0.14 & 0.59 & 1.08 & -0.10 \\
\hline Bihar & 53 & 0.51 & 0.12 & 0.30 & 0.72 & -0.34 \\
\hline Gujarat & 53 & 1.28 & 0.12 & 1.04 & 1.54 & -0.04 \\
\hline Haryana & 53 & 1.42 & 0.20 & 0.95 & 1.77 & -0.67 \\
\hline Karnataka & 53 & 1.07 & 0.06 & 0.95 & 1.18 & 0.05 \\
\hline Kerala & 53 & 1.15 & 0.12 & 0.92 & 1.34 & 0.00 \\
\hline Madhya Pradesh & 53 & 0.81 & 0.11 & 0.58 & 0.97 & -0.65 \\
\hline Maharashtra & 53 & 1.39 & 0.17 & 1.10 & 1.68 & -0.18 \\
\hline Manipur & 53 & 0.83 & 0.17 & 0.52 & 1.14 & -0.38 \\
\hline Orissa & 53 & 0.76 & 0.07 & 0.64 & 0.91 & 0.14 \\
\hline Punjab & 53 & 1.50 & 0.19 & 1.08 & 1.81 & -0.59 \\
\hline Rajasthan & 53 & 0.92 & 0.10 & 0.73 & 1.14 & 0.06 \\
\hline Tamil Nadu & 53 & 1.13 & 0.17 & 0.87 & 1.45 & 0.26 \\
\hline Tripura & 53 & 0.94 & 0.09 & 0.69 & 1.10 & -0.77 \\
\hline Uttar Pradesh & 53 & 0.71 & 0.12 & 0.49 & 0.90 & -0.66 \\
\hline West Bengal & 53 & 1.01 & 0.10 & 0.86 & 1.20 & 0.13 \\
\hline
\end{tabular}


Table 2: Traditional Unit root tests without structural breaks

\begin{tabular}{llll}
\hline Series & ADF Test & KPSS Test & $\begin{array}{l}\text { Schmidt and Philips } \\
\text { LM Unit root test }\end{array}$ \\
\hline Andhra Pradesh & -0.632 & $0.218^{* * *}$ & -2.491 \\
Assam & -0.631 & $0.161^{* *}$ & -1.553 \\
Bihar & -0.663 & $0.158^{* *}$ & -1.525 \\
Gujarat & -1.689 & 0.057 & $-5.096^{* * *}$ \\
Haryana & -1.703 & $0.160^{* *}$ & -1.740 \\
Karnataka & -2.228 & $0.143^{*}$ & $-4.088^{* * *}$ \\
Kerala & -1.160 & 0.062 & $-3.209^{* *}$ \\
Madhya Pradesh & -1.045 & $0.213^{* *}$ & -2.027 \\
Maharashtra & -1.194 & $0.121^{*}$ & -2.064 \\
Manipur & -1.821 & $0.250^{* * *}$ & -1.211 \\
Orissa & -2.440 & 0.072 & -2.253 \\
Punjab & -1.801 & $0.235^{* * *}$ & -0.878 \\
Rajasthan & -2.454 & 0.066 & $-3.911^{* * *}$ \\
Tamil Nadu & -0.409 & $0.160^{* *}$ & -1.321 \\
Tripura & -2.564 & 0.065 & -2.796 \\
Uttar Pradesh & -0.478 & $0.224^{* * *}$ & -1.019 \\
West Bengal & -1.361 & 0.051 & $-4.312^{* * *}$ \\
\hline
\end{tabular}

Notes: Sample consisted of annual data for the period 1960 - 2012. The unit root tests were preformed on the series

$y_{i t}=\ln \left(\frac{\text { SDP Per Capita }}{\text { Average SDP Per Capita }}\right)$

with the assumption of an intercept and trend in the series. The lag lengths were selected using the Bayesian Information criteria (BIC). The null hypothesis for ADF and LM test is a unit root, whereas the null hypothesis for the KPSS test is stationarity. The maximum lag length was 10 based on the formula LagLength = $\operatorname{int}\left(12\left(\frac{T}{100}\right)^{0.25}\right)$ suggested by Hayashi (2000, pp. 594). The critical values for each test are as follows:

\begin{tabular}{llll}
\hline Test & \multicolumn{3}{l}{ Critical Values } \\
& $1 \%$ & $5 \%$ & $10 \%$ \\
\hline ADF & -3.58 & -2.93 & -2.60 \\
KPSS & 0.216 & 0.146 & 0.119 \\
Schmidt and Philips & -3.73 & -3.11 & -2.80 \\
\hline
\end{tabular}


Table 3. Cross-section correlation of the errors in the $\operatorname{ADF}(p)$ regression for SDP per Capita for the 17 Major Indian states.

\begin{tabular}{|c|c|c|c|c|}
\hline & $\mathrm{P}=1$ & $\mathrm{P}=2$ & $\mathrm{P}=3$ & $\mathrm{P}=4$ \\
\hline \multicolumn{5}{|c|}{ Panel A = Actual SDP per capita } \\
\hline$\overline{\hat{\rho}}$ & 0.300 & 0.233 & 0.228 & 0.234 \\
\hline CD & $24.53 * * *$ & $19.03 * * *$ & $18.65 * * *$ & $19.08 * * *$ \\
\hline \multicolumn{5}{|c|}{ Panel B $=$ Relative SDP per capita [ In(SDP per capita in state i/National GDP per capita)] } \\
\hline$\overline{\hat{\rho}}$ & 0.047 & 0.052 & 0.051 & 0.053 \\
\hline CD & $3.839 * * *$ & $4.209 * * *$ & $4.156^{* * *}$ & $4.365 * * *$ \\
\hline
\end{tabular}

Notes: The cross-sectional dependence (CD) test statistic is proposed in Pesaran (2004) for testing for crosssectional dependence in panels. All statistics are based on univariate $\operatorname{AR}(p)$ specifications in the level of the variables with $p \leq 4$. The null hypothesis is that output innovations are cross-sectionally independent. The $10 \%$, $5 \%$ and $1 \%$ critical values for the CD statistic are $1.64,1.96$ and 2.57 respectively.

$\overline{\hat{\rho}}$

$\hat{\rho}$ is the simple average of the pair-wise cross-sectional coefficients of the individual $A D F(p)$ regressions for lag lengths $-(p)=1,2,3$ and 4 . 
Table 4: CIPS test statistics (adjusting for cross-sectional dependence) for individual states

\begin{tabular}{lllll}
\hline & $\mathrm{P}=1$ & $\mathrm{P}=2$ & $\mathrm{P}=3$ & $\mathrm{P}=4$ \\
\hline Relative SDP per capita [ In(SDP per capita & in & state i/National & GDP per capita) ] & \\
\hline Andhra Pradesh & -2.51 & $-3.43^{*}$ & -2.95 & -2.99 \\
Assam & $-3.63^{*}$ & -3.01 & -2.75 & -2.90 \\
Bihar & -2.11 & -0.09 & -0.65 & -1.02 \\
Gujarat & $-5.48^{* * *}$ & -3.41 & -3.30 & $-3.48^{*}$ \\
Haryana & -3.40 & -3.02 & -2.20 & -1.93 \\
Karnataka & $-3.70^{*}$ & -2.60 & -2.26 & -1.91 \\
Kerala & $-3.68^{*}$ & -2.54 & -2.02 & -2.15 \\
Madhya Pradesh & $-6.80^{* * *}$ & $-4.87^{* * *}$ & -2.98 & -2.93 \\
Maharashtra & -2.92 & -3.04 & -2.99 & -3.35 \\
Manipur & $-3.91^{* *}$ & -3.24 & -2.76 & -3.16 \\
Orissa & $-4.28^{* *}$ & -2.92 & -2.35 & -2.97 \\
Punjab & -2.12 & -1.99 & -1.93 & -2.02 \\
Rajasthan & $-4.28^{* *}$ & -3.14 & -2.45 & -2.57 \\
Tamil Nadu & $-3.50^{*}$ & -3.12 & -2.93 & -2.96 \\
Tripura & -1.98 & -2.32 & -2.96 & -3.14 \\
Uttar Pradesh & $-4.24^{* *}$ & -3.14 & -3.09 & -3.09 \\
West Bengal & -3.06 & -2.28 & -2.26 & -2.51 \\
\hline
\end{tabular}

Notes: The null hypothesis is that the series has a unit root. The test was performed under the assumption there is an intercept and linear trend in the series (case 3 in Pesaran, 2004). The 10\%, 5\% and $1 \%$ critical values for case 3 with $\mathrm{T}=50, \mathrm{~N}=20$ from Pesaran (2004) are $-3.44,-3.79$ and -4.52 respectively. ${ }^{*}\left({ }^{* *}\right){ }^{* * *}$ denotes statistical significance at the $10 \%, 5 \%$ and $1 \%$ levels respectively. 
Table 5: KPSS and LM Unit root tests with two structural breaks

\begin{tabular}{|c|c|c|c|c|c|c|}
\hline \multirow[b]{2}{*}{ Series } & \multicolumn{3}{|c|}{$\begin{array}{l}\text { Lee and Strazicich (2003) LM } \\
\text { Unit root test }\end{array}$} & \multicolumn{3}{|c|}{$\begin{array}{l}\text { Carrion-i-Silvestre and Sansó (2007) } \\
\text { KPSS Unit root test. }\end{array}$} \\
\hline & $\begin{array}{c}\text { Test } \\
\text { statistic }\end{array}$ & TB1 & TB2 & $\begin{array}{c}\text { Test } \\
\text { statistic }\end{array}$ & TB1 & TB2 \\
\hline Andhra Pradesh & $-6.25 * *$ & 1979 & 1992 & 0.039 & 1967 & 1974 \\
\hline Assam & -5.12 & 1979 & 1991 & 0.046 & 1979 & 1984 \\
\hline Bihar & $-6.88 * * *$ & 1985 & 2001 & 0.042 & 1983 & 2004 \\
\hline Gujarat & $-6.76^{* * *}$ & 1984 & 1998 & $0.056^{*}$ & 1993 & 2001 \\
\hline Haryana & $-7.38 * * *$ & 1969 & 1996 & $0.078 * *$ & 1965 & 1968 \\
\hline Karnataka & $-5.56^{*}$ & 1975 & 2000 & 0.050 & 1966 & 1990 \\
\hline Kerala & $-5.43 *$ & 1980 & 2004 & 0.052 & 1969 & 1993 \\
\hline Madhya Pradesh & $-5.93 * *$ & 1987 & 2004 & 0.032 & 1986 & 2003 \\
\hline Maharashtra & -5.13 & 1972 & 1998 & 0.030 & 1973 & 1991 \\
\hline Manipur & $-6.96 * * *$ & 1990 & 2005 & 0.033 & 1965 & 1986 \\
\hline Orissa & $-5.83 * *$ & 1979 & 2002 & $0.081 * *$ & 1979 & 2002 \\
\hline Punjab & $-6.25^{* *}$ & 1980 & 1991 & 0.042 & 1979 & 1992 \\
\hline Rajasthan & $-5.88 * *$ & 1978 & 1999 & 0.033 & 1978 & 1999 \\
\hline Tamil Nadu & -4.6 & 1976 & 2000 & 0.046 & 1978 & 2000 \\
\hline Tripura & $-6.05 * *$ & 1988 & 1999 & $0.080 * *$ & 1991 & 1999 \\
\hline Uttar Pradesh & -5.26 & 1992 & 2004 & 0.054 & 1967 & 1991 \\
\hline West Bengal & $-6.28 * *$ & 1978 & 1990 & $0.078 * *$ & 1983 & 1996 \\
\hline
\end{tabular}

Notes: Both the tests were performed under the assumption of break in Intercept and Trend. $\mathrm{TB}_{1}$ and $\mathrm{TB}_{2}$ are the dates of the structural breaks. $\lambda_{j}$ denotes the location of the breaks. For the LM unit root test the null distribution of the LM test depends on the relative location of the breaks. The critical values for LM unit root test are presented in the table below. The $10 \%, 5 \%$ and $1 \%$ critical values for Carrion-i-Silvestre and Sansó (2007) KPSS Unit root test are $0.0552,0.0665$ and 0.0936 respectively. The *, $* *, * * *$ denotes statistical significance at the $10 \%, 5 \%$ and $1 \%$ levels respectively. The maximum lag length for LM test was 10 based on the formula LagLength $=\operatorname{int}\left(12\left(\frac{T}{100}\right)^{0.25}\right)$ suggested by Hayashi (2000, pp. 594).

\begin{tabular}{|c|c|c|c|c|c|c|c|c|c|}
\hline \multicolumn{10}{|c|}{ Critical values for LM unit root test $\left(\mathrm{S}_{\mathrm{t}-1}\right)$} \\
\hline \multicolumn{10}{|c|}{ Model CC (Break in Intercept and Trend) } \\
\hline$\lambda_{2}$ & & 0.4 & & & 0.6 & & & 0.8 & \\
\hline$\lambda_{1}$ & $1 \%$ & $5 \%$ & $10 \%$ & $1 \%$ & $5 \%$ & $10 \%$ & $1 \%$ & $5 \%$ & $10 \%$ \\
\hline 0.2 & -6.16 & -5.59 & -5.27 & -6.41 & -5.74 & -5.32 & -6.33 & -5.71 & -5.33 \\
\hline 0.4 & - & - & - & -6.45 & -5.67 & -5.31 & -6.42 & -5.65 & -5.32 \\
\hline 0.6 & - & - & - & - & - & - & -6.32 & -5.73 & -5.32 \\
\hline
\end{tabular}


Table 6: Results for the individual states of the Panel KPSS test with multiple structural breaks

\begin{tabular}{lllllll}
\hline Series & $\begin{array}{l}\text { KPSS test statistic } \\
\text { (Bartlett kernel) }\end{array}$ & $\mathbf{T B}_{\mathbf{1}}$ & $\mathbf{T B}_{\mathbf{2}}$ & $\mathbf{T B}_{\mathbf{3}}$ & $\mathbf{T B}_{\mathbf{4}}$ & $\mathbf{T B}_{\mathbf{5}}$ \\
\hline Andhra Pradesh & $0.112^{* * *}$ & 1967 & 1974 & 1980 & 1986 & 1995 \\
Assam & $0.075^{* *}$ & 1973 & 1979 & 1984 & 1995 & 2005 \\
Bihar & 0.038 & 1983 & 1994 & 2004 & - & - \\
Gujarat & 0.044 & 1998 & - & - & - & - \\
Haryana & 0.032 & 1965 & 1968 & 1996 & - & - \\
Karnataka & 0.018 & 1965 & 1972 & 1978 & 1990 & - \\
Kerala & 0.049 & 1964 & 1976 & 1980 & 1987 & 1994 \\
Madhya Pradesh & 0.057 & 1964 & 1974 & 1979 & 1986 & 2003 \\
Maharashtra & 0.023 & 1972 & 1981 & 1991 & 1997 & - \\
Manipur & $0.182^{* * *}$ & 1965 & 1970 & 1988 & 2005 & - \\
Orissa & 0.029 & 1961 & 1979 & 2002 & - & - \\
Punjab & $0.142^{* * *}$ & 1965 & 1979 & 1992 & - & - \\
Rajasthan & 0.032 & 1967 & 1970 & 1978 & 1999 & - \\
Tamil Nadu & 0.038 & 1969 & 1973 & 2000 & - & - \\
Tripura & 0.044 & 1962 & 1982 & 1987 & 1993 & 2000 \\
Uttar Pradesh & $0.098^{* *}$ & 1967 & 1971 & 1975 & 1990 & 2007 \\
West Bengal & 0.028 & 1979 & 1987 & 1996 & - & - \\
\hline Non & & & - \\
\hline
\end{tabular}

Notes: $* *$ and $* * *$ denote significance at the $5 \%$ and $1 \%$ levels, respectively. Significance is determined using Bootstrap critical values based on a Monte Carlo simulation with 20,000 replications proposed by Maddala and $\mathrm{Wu}$ (1999). The procedure for calculating Bootstrap critical values is summarised in Appendix 1. The test was performed allowing for a maximum of five breaks in Intercept and Trend. 
Table 7: Results of Panel Unit root tests.

\begin{tabular}{|c|c|c|c|c|c|}
\hline \multicolumn{6}{|c|}{ Panel A: Pesaran (2004) CIPS test } \\
\hline & $\mathrm{P}=1$ & $\mathrm{P}=2$ & $\mathrm{P}=3$ & & $\mathrm{P}=4$ \\
\hline & $-3.623 * * *$ & $-2.832 * *$ & -2.5 & & $-2.651 *$ \\
\hline \multicolumn{6}{|c|}{ Panel B: Hadri (2000) and Carrion-i-Silvestre et al. (2005) KPSS tests } \\
\hline & \multirow{2}{*}{\multicolumn{2}{|c|}{$\begin{array}{l}\text { KPSS test statistic } \\
\text { (Using Bartlett kernel) }\end{array}$}} & \multicolumn{3}{|c|}{ Bootstrap critical values } \\
\hline & & & $10 \%$ & $5 \%$ & $1 \%$ \\
\hline No Breaks (Homogenous) & 3.544 & & 3.825 & 4.993 & 7.584 \\
\hline No Breaks (Heterogeneous) & 2.461 & & 3.733 & 4.381 & 6.084 \\
\hline Breaks (Homogenous) & 9.513 & & 14.887 & 15.923 & 18.156 \\
\hline Breaks (Heterogeneous) & 19.190 & & 21.008 & 22.955 & 26.363 \\
\hline \multicolumn{6}{|c|}{ Panel C: IM et al. (2005) Panel LM Unit root tests } \\
\hline & \multicolumn{5}{|c|}{ Panel LM test statistic } \\
\hline No Breaks & \multicolumn{5}{|c|}{$-5.028^{* * *}$} \\
\hline One Break & \multicolumn{5}{|l|}{$-9.983 * * *$} \\
\hline Two Breaks & \multicolumn{5}{|l|}{$-13.003 * * *$} \\
\hline \multicolumn{6}{|c|}{ Panel D: Bai and Carrion-i-Silvestre (2009) Unit root test } \\
\hline $\mathrm{Z}$ & \multicolumn{5}{|c|}{$1.388^{*}$} \\
\hline $\mathrm{P}_{\mathrm{m}}$ & \multicolumn{5}{|l|}{$2.745 * * *$} \\
\hline $\mathrm{P}$ & \multicolumn{5}{|l|}{$56.642 * * *$} \\
\hline
\end{tabular}

Notes: (1.) $* *$ and $* * *$ denotes significance at the $5 \%$ and $1 \%$ levels, respectively. (2.) The $10 \%, 5 \%$ and $1 \%$ critical values for case III with $\mathrm{T}=50, \mathrm{~N}=20$ from Pesaran (2004) are $-2.63,-2.71$ and -2.85 respectively. (3.) Bootstrap critical values for Hadri (2000) and Carrion-i-Silvestre et al. (2005) KPSS tests are based on a Monte Carlo simulation with 20,000 replications proposed by Maddala and $\mathrm{Wu}$ (1999). The procedure for calculating Bootstrap critical values is summarised in Appendix 1 (4.) The 1, 5 and 10\% critical values for the IM et al. (2005) panel LM unit root tests are $-2.236,-1.645$ and -1.282 respectively. (5.) The null hypothesis for Pesaran (2004) and IM et al. (2005) tests is that the panel has a unit root, whereas the null hypothesis for Hadri (2000) and Carrion-i-Silvestre et al. (2005) KPSS tests is stationarity. (6.) The null hypothesis for Bai and Carrion-i-Silvestre (2009) test is Unit root. (7.) The 1, 5 and $10 \%$ critical values for $\mathrm{Z}$ and $\mathrm{P}_{\mathrm{m}}$ statistics are $2.326,1.645$ and 1.282 respectively and the corresponding critical values for $P$ statistics are 56.06, 48.60 and 44.90 respectively. (8.) The maximum lag length for Panel LM unit root test and Bai and Carrion-i-Silvestre (2009) Unit root test was 10 based on the formula LagLength $=\operatorname{int}\left(12\left(\frac{T}{100}\right)^{0.25}\right)$ suggested by Hayashi (2000, pp. 594). (9.) For IM et al. (2005) Panel LM Unit root tests, the optimal lag length was selected separately for each series by following a general to specific procedure, that relies on starting from the maximum lag and going down to the last significant lagged term (determined by its t-statistics). (10.) The optimal lag length for Bai and Carrion-i-Silvestre (2009) Unit root test was determined using Bayesian information criterion (BIC). 
Table 8: Major Events in States around the Break- Dates

\begin{tabular}{|c|c|c|}
\hline Series & Break dates & Major events around the break dates \\
\hline $\begin{array}{l}\text { Andhra } \\
\text { Pradesh }\end{array}$ & $\begin{array}{l}1967,1974,1979,1980, \\
1986,1992,1995\end{array}$ & $\begin{array}{l}\text { 1969: Political crisis due to Telangana agitation } \\
\text { 1972: Political crisis due to 'Jai Andhra' movement } \\
\text { 1983-84: regime change as TDP (Telugu Desam party), established } \\
\text { by N.T. Ramarao (NTR), came to power and Congress Party lost } \\
\text { election first time after independence. } \\
\text { NTR regime (1983-89) was the period of rapid economic growth } \\
\text { due to educational reforms, local government empowerment, } \\
\text { irrigation and electricity improvements and corruption controls } \\
\text { measures. } \\
\text { 1989: 'IT (Information Technology) revolution' mainly in } \\
\text { Hyderabad }\end{array}$ \\
\hline Assam & $\begin{array}{l}\text { 1973, 1979, 1984, 1991, } \\
1995,2005\end{array}$ & $\begin{array}{l}\text { 1979: Beginning of 'Assam movement' against undocumented } \\
\text { immigrants } \\
\text { 1985: Assam movement ended following 'Assam accord' } \\
\text { 1990: president rule was imposed due to deteriorating law and order } \\
\text { situation because of indirect support of AGP (Asom Gana Parishad) } \\
\text { to ULFA (United Liberation Front of Assam) terrorist activities. } \\
\text { Subsequently, military was deployed and ULFA was banned. } \\
\text { 2005: attack on oil pipelines by a terrorist organisation ULFA. }\end{array}$ \\
\hline Bihar & $\begin{array}{l}\text { 1983, 1985, 1994, } \\
2001,2004\end{array}$ & $\begin{array}{l}\text { 1984: anti Sikh riots in northern India including Bihar following the } \\
\text { assassination of Indira Gandhi } \\
\text { 1990-2005: characterized as Lalu Prasad/Rabri Devi era (Rashtriya } \\
\text { Janata Dal (RJD) Party) marked by complete collapse of economy, } \\
\text { excessive rise in crimes and mass migration to other states } \\
\text { 2000: divided into two states; Bihar (northern part) and Jharkhand } \\
\text { (southern part and more industrialized region) } \\
\text { 2005: Change in political regime as Nitish Kumar (Janata Dal } \\
\text { (United) became CM. }\end{array}$ \\
\hline Gujarat & $1984,1993,1998,2001$ & $\begin{array}{l}\text { 1981,85: anti reservation agitation } \\
\text { 1994: breaking out of plague epidemic predominantly in Surat } \\
\text { resulted in mass migration } \\
\text { 1998: severe tropical cyclone hit several districts in coastal areas of } \\
\text { Gujarat and Rajasthan. } \\
\text { 2001: Massive earthquake leading to huge loss of lives and property }\end{array}$ \\
\hline Haryana & $1965,1968,1969,1996$ & $\begin{array}{l}\text { 1966: came into existence as separate administrative entity, was the } \\
\text { part of Punjab before } \\
\text { 1996: change in political regime from Congress party to HVP } \\
\text { (Haryana Vikas Party), a breakaway party from Congress, which } \\
\text { merged again into Congress party in } 1994 \text {. }\end{array}$ \\
\hline Karnataka & $\begin{array}{l}1965,1966,1972,1975, \\
1978,1990,2000\end{array}$ & $\begin{array}{l}\text { 1962-68: development of various agricultural, irrigation, industrial } \\
\text { and transport projects like 'Sharavathi Hydroelectric Project' and } \\
\text { 'Cauvery Basin Irrigation Project.' } \\
\text { 1974: Enactment of 'New land Reform Act' which abolished all } \\
\text { forms of tenancies and made tenants owner of the land they } \\
\text { cultivated. One major drawback of this reform was provision of } \\
\text { 'land ceilings' which increased the proportion of small and } \\
\text { marginal farmers and adversely affect the agriculture. } \\
\text { 1980s: the emergence of Karnataka as IT capital of India. This took } \\
\text { major upturn in early 1990s due to STPI (Software Technology } \\
\text { Parks of India) scheme (1988-1991) and trade liberalization } \\
\text { policies in early 1990s. } \\
\text { 1997: Karnataka became the first state to announce State IT policy. }\end{array}$ \\
\hline Kerala & $\begin{array}{l}1964,1969,1976, \\
1980,1987,1993,1994,2004\end{array}$ & $\begin{array}{l}\text { 1970: Land reform Act which ended the feudal system and ensured } \\
\text { rights of tenants on land came into force. Before that few other land } \\
\text { reforms bills were passed in } 1960,1963,1964 \text { and } 1969 \text {. } \\
1976,79,89 \text { and 1992: broad gauge railway lines connecting }\end{array}$ \\
\hline
\end{tabular}




\begin{tabular}{|c|c|c|}
\hline & & $\begin{array}{l}\text { various cities became operational. } \\
\text { 2004: the Indian ocean tsunami caused heavy damage and loss of } \\
\text { life to coastal villages of Kerala. }\end{array}$ \\
\hline Madhya & 1964,1974,1979,1986, & 1984:Bhopal Gas tragedy, world's worst industrial disaster \\
\hline Pradesh & $1987,2003,2004$ & $\begin{array}{l}\text { 2000: Formation of Chattisgarh, a separate state, from Madhya } \\
\text { Pradesh }\end{array}$ \\
\hline Maharashtra & $\begin{array}{l}\text { 1972,1973,1981,1991, } \\
1997,1998\end{array}$ & $\begin{array}{l}\text { 1972: Drought in Maharashtra } \\
\text { 1993: Latur Eartquake } \\
\text { 1992-93: Mumbai riots followed by Mumbai bombings } \\
\text { 2000: Introduction of 'special economic zones' to create a } \\
\text { transparent system and procedure for enhancing productivity and } \\
\text { ease of doing business }\end{array}$ \\
\hline Orissa & $1961,1979,2002$ & $\begin{array}{l}\text { 1962: Balimela Reservoir Project was started } \\
\text { 1964: HAL (Hindustan Aeronautics Limited) plan was set up. } \\
\text { 1981: NALCO (National Aluminium Company Limited), one of } \\
\text { Asia's largest integrated aluminium complex was founded with a } \\
\text { headquarter in Bhubaneswar. } \\
\text { 1999: a major cyclone hit Orissa causing huge economic damage } \\
\text { and loss of human lives. }\end{array}$ \\
\hline Punjab & $\begin{array}{l}\text { 1965,1979,1980,1991, } \\
1991\end{array}$ & $\begin{array}{l}\text { 1965: start of green revolution (application of high yielding variety } \\
\text { of seeds which double the production of wheat and rice manifolds). } \\
\text { 1966: Punjab was split into three states: Punjab, Haryana and } \\
\text { Himachal Pradesh } \\
\text { 1979-1984: insurgency period as Sikh militants demanded } \\
\text { autonomy for Punjab and resorted to violence. } \\
\text { 1984: operation 'Blue Star' to combat Sikh insurgency } \\
\text { 1984: anti-sikh riots after the assassination of Indira Gandhi (prime } \\
\text { minister) } \\
\text { 1992: Congress party came to power after } 5 \text { years (roughly) of } \\
\text { president rule. }\end{array}$ \\
\hline Rajasthan & $1967,1970,1978,1999$ & $\begin{array}{l}\text { 1967-1970: increase in the spending on education and health (above } \\
\text { national average in 1970) } \\
\text { 1977-1980: period of political uncertainty before Congress Party } \\
\text { came into power in June, } 1980 \\
\text { 1998: Shift in political leadership from BJP to Congress Party }\end{array}$ \\
\hline Tamil Nadu & $\begin{array}{l}1969,1973,1976, \\
1978,2000\end{array}$ & $\begin{array}{l}\text { 1965: Anti Hindi agitation } \\
\text { 1967: Regime change as DMK (Dravida Munnetra Kazhagam) took } \\
\text { control of the state, ending the stronghold of Congress. } \\
\text { 1972: DMK was split and AIADMK (All India Anna Dravida } \\
\text { Munnetra Kazhagam) was formed out of it, } \\
\text { 1977: AIADMK came to power defeating DMK } \\
\text { 1995-1996: setting up of manufacturing plant by global auto } \\
\text { manufacturers like Hyundai, Ford and Mitsubishi } \\
\text { 1997: IT (information technology) policy paved the path for } \\
\text { sustained growth of IT industry } \\
\text { 2004: Indian Ocean tsunami which severely affected the east coast } \\
\text { of Tamil Nadu. }\end{array}$ \\
\hline Uttar Pradesh & $\begin{array}{l}\text { 1967,1971,1975,1990,1991, } \\
1993,1999,2007\end{array}$ & $\begin{array}{l}\text { 1965: start of green revolution benefitted the western region } \\
\text { 1992: Demolition of Babri Masjid provoking violent riots later on } \\
\text { 2000: Uttarakhand was formed out of Uttar Pradesh } \\
\text { 2007: onset of Ms Mayawati government, the first government to } \\
\text { complete its full term after a period of } 16 \text { years }\end{array}$ \\
\hline West Bengal & $\begin{array}{l}1978,1979,1983,1987, \\
1990,1996\end{array}$ & $\begin{array}{l}\text { 1974: Smallpox epidemic } \\
\text { 1977: Major shift in politics when CPI (M) (Communist Party of } \\
\text { India (Marxist)) came to power, defeating Congress party, and } \\
\text { governed the state till } 2011 \text {. } \\
\text { 1979: major drought } \\
\text { 2000: Change in leadership from Jyoti Basu (CM for } 23 \text { years) to }\end{array}$ \\
\hline
\end{tabular}


Buddhadeb Bhatacharya

Notes: The break dates in this table is a superset of all the significant structural breaks reported LM 2 breaks unit root test, KPSS 2 breaks stationarity test and KPSS Multiple break stationarity test. 
Figure 1: Graphs of Relative SDP per capita compared to the National Per Capita GDP.

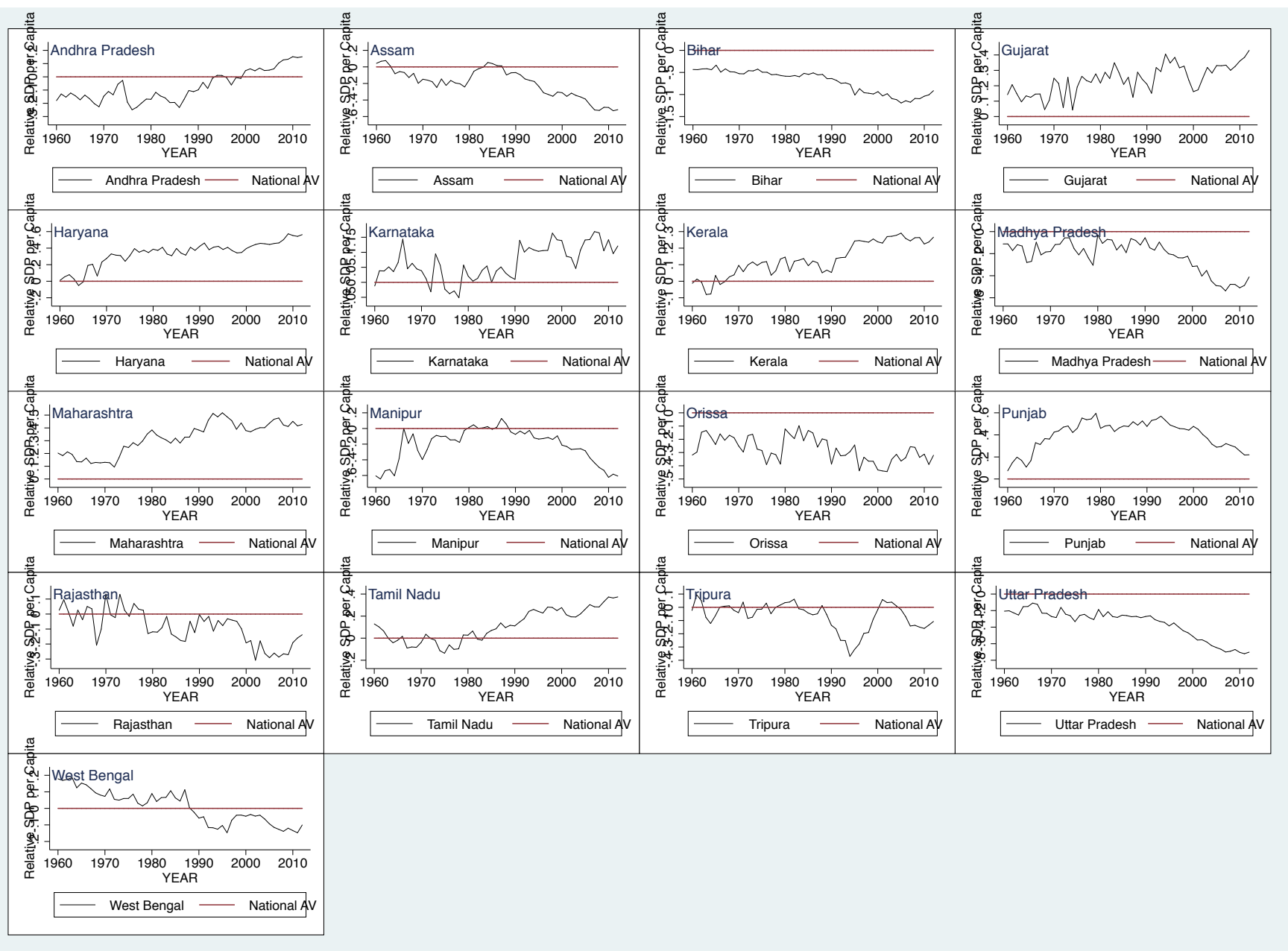


Figure 2: Multiple structural breaks in the Relative SDP per capita of Uttar Pradesh and Assam.

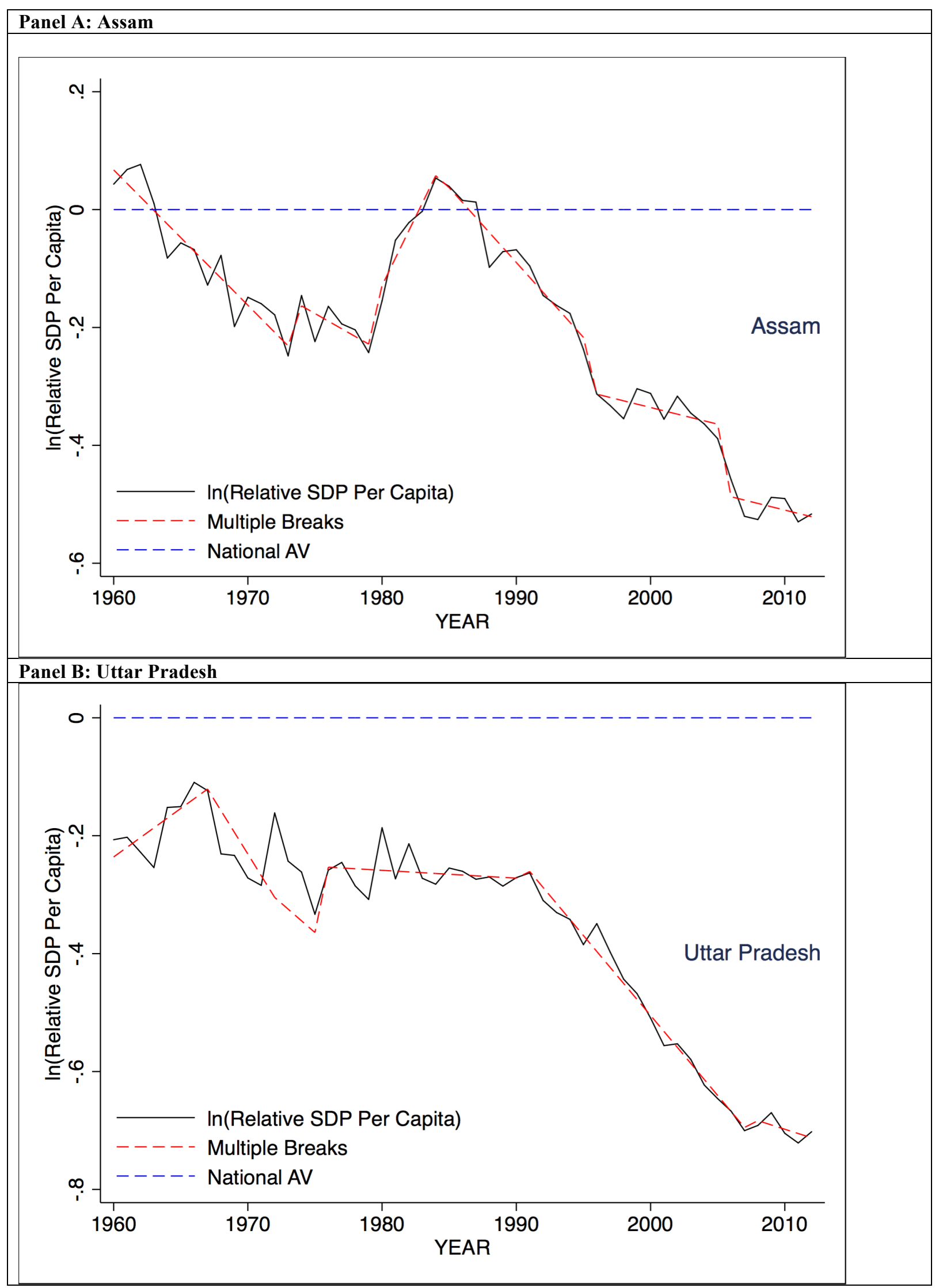




\section{Appendix 1: Summary of Maddala and Wu (1999) Bootstrap procedure for calculating Critical values}

Maddala and $\mathrm{Wu}$ (1999) propose a bootstrap methodology to get the empirical distribution of the test statistics to make inferences that aren't affected by cross-correlated errors in the data. The method proposed by Maddala and Wu (1999) extends the method proposed by Li and Maddala (1996) for univariate time series to a panel setting.

This methodology relies on generating a bootstrap sample $y^{*}=\alpha \beta_{0}+\epsilon^{*}$, such that $\epsilon^{*}$ in the bootstrap sample is taken from $\epsilon^{0}=y-\alpha \beta_{0}$ of original sample. In this case, as we are interested in a Panel data, the bootstrap sample of error terms $\epsilon^{0}$ would be from:

$$
\Delta y_{i t}=\eta_{i} \Delta y_{i t-1}+\epsilon_{i t}^{0}
$$

However, due to cross-correlations among $\epsilon_{i t}^{0}$, one can't resample $\epsilon_{i t}^{0}$ directly. Maddala and $\mathrm{Wu}$ (1999) recommend resampling $\epsilon_{i t}^{0}$ with the cross-section index fixed i.e. picking up $\epsilon_{i t}^{0}$ from $\epsilon_{t}^{0}=$ $\left[\epsilon_{1 t}^{0}, \epsilon_{2 t}^{0}, \ldots \ldots \epsilon_{N t}^{0}\right]$ to get $\epsilon_{t}^{*}$. This will ensure that the cross-correlation structure of the error terms is not altered due to resampling.

Following this technique, the bootstrap sample generated is:

$$
\begin{gathered}
y_{i t}^{*}=y_{i t-1}^{*}+u_{i t}^{*} \text { with } y_{i 0}^{*}=0 \\
u_{i t}^{*}=\hat{\eta}_{i} u_{i t-1}^{*}+\epsilon_{i t}^{*} \text { with } u_{i, 0}^{*}=\sum_{j=0}^{m} \hat{\eta}_{i}^{j} \epsilon_{-j}^{*}
\end{gathered}
$$

such that $\hat{\eta}_{i}$ 's are collected from regression in equation $(A 1)$ conducted over randomly selected bootstrap samples. We conducted the above set of estimations 20,000 times to generate the empirical distributions, which was subsequently used to generate the critical values. The estimations were carried out using the Gauss code provided by Prof. Josep Lluís Carrion-i-Silvestre. 


\section{Re-examination of convergence hypothesis among Indian states in panel stationarity testing framework with structural breaks}

\section{Ankita Mishra \& Vinod Mishra}

To cite this article: Ankita Mishra \& Vinod Mishra (2017): Re-examination of convergence hypothesis among Indian states in panel stationarity testing framework with structural breaks, Applied Economics, DOI: 10.1080/00036846.2017.1319559

To link to this article: http://dx.doi.org/10.1080/00036846.2017.1319559

\section{曲 Published online: 25 Apr 2017.}

\section{Submit your article to this journal $₫$}

Џ Article views: 36

Q View related articles $\sqsubset$

View Crossmark data \lceil 


\title{
Re-examination of convergence hypothesis among Indian states in panel stationarity testing framework with structural breaks
}

\author{
Ankita Mishra $\mathbb{( i}^{a}$ and Vinod Mishra $\mathbb{1}^{b}$ \\ aSchool of Economics, Finance and Marketing, RMIT University, Melbourne, Australia; 'Department of Economics, Monash University, \\ Clayton, VIC, Australia
}

ABSTRACT

This article examines the conditional income convergence hypothesis for 17 major states in India for the period of 1960-2012. Univariate stationarity tests without structural breaks provide evidence against the convergence hypothesis. However, when two or more structural breaks are applied in per capita income series, the incomes of around 11-13 states are found to stochastically converge to the national average. This finding supports the convergence hypothesis for the panel as a whole after accounting for two data features, cross-sectional dependence and structural breaks in incomes, using a unified panel stationarity testing framework.

\section{KEYWORDS}

India; panel unit root: structural break;

convergence

JEL CLASSIFICATION O40; C12

\section{Introduction}

Economic growth models based on new growth theory envision poor regions catching up with rich regions in terms of income per capita. According to growth models, the payoffs of additional capital or better technology are greater for a poor economy. Hence, poor economies should be able to increase their growth rate at a faster rate than richer economies, enabling them to catch up.

Various studies in the literature have taken an empirical view to determine whether the economies of different groups of countries have actually caught up or converged (Mankiw, Romer, and Weil 1992; Evans 1996; Evans 1997), and diverse regions (or states) within a single large country have also been considered. These latter studies have primarily focused on the United States (Young, Higgins, and Data 2008; Carlino and Mills 1993). The two main techniques used to investigate the convergence hypothesis are cross-sectional growth equation estimates (Barro and Sala-i-Martin 1992; Barro and Martin 1995; Mankiw, Romer, and Weil 1992) and time series unit root testing (Bernard and Durlauf 1995; Carlino and Mills 1993; Fleissig and Strauss
2001; Strazicich, Lee, and Day 2004). The convergence hypothesis has been found to hold true for varied samples of industrial countries and their regions in cross-sectional studies, although time series evidence remains ambiguous (Strazicich, Lee, and Day 2004).

The notion of convergence, defined as inclusive growth, holds a pivotal place in Indian central planning. Even though inter-state variation in growth rates has fallen in India over the years, imbalances in regional growth still remain acute in India. Bandyopadhyay (2011) has argued that some of the richest states in India (e.g. Gujarat and Maharashtra) are akin to middle-income countries, such as Poland and Brazil, in their level of development, whereas the poorest states of Bihar, Uttar Pradesh and Orissa are similar to some of the poorest sub-Saharan countries in Africa.

Various studies have examined the convergence hypothesis for Indian states. The majority of these studies have found little support for absolute convergence $^{1}$ among Indian states. Rather, these studies have found evidence in favour of absolute divergence (Marjit and Mitra 1996; Ghosh and De 1998; Nagaraj, Varoudakis, and Veganzones 2000;

\footnotetext{
CONTACT Vinod Mishra vinod.mishra@monash.edu E Department of Economics, Monash University, Clayton VIC - 3800, Australia

${ }^{1}$ The three competing hypotheses on convergence as defined by Galor (1996) are: (1) the absolute convergence hypothesis, where per capita income of countries (or regions) converge to one another in the long term, irrespective of their initial conditions; (2) the conditional convergence hypothesis, where per capita income of countries that are identical in their structural characteristics converge to one another in the long term, irrespective of their initial conditions; and (3) the club convergence hypothesis, where per capita income of countries that are identical in their structural characteristics converge to one another in the long term, provided that their initial conditions are similar.

(c) 2017 Informa UK Limited, trading as Taylor \& Francis Group
} 
Rao, Shand, and Kalirajan 1999; Dasgupta et al. 2000; Sachs, Bajpai, and Ramiah 2002; Trivedi 2002; Shetty 2003; Bhattacharya and Sakthivel 2004; Baddeley, McNay, and Cassen 2006; Kar and Sakthivel 2007; Nayyar 2008; Ghosh 2008; Ghosh 2010; Ghosh 2012; Kalra and Sodsriwiboon 2010). In only a few cases, studies have confirmed absolute convergence, and several other studies have found support for conditional convergence (Dholakia 1994; Cashin and Sahay 1996a; Cashin and Sahay 1996b; Nagaraj, Varoudakis, and Veganzones 2000; Sachs, Bajpai, and Ramiah 2002; Trivedi 2002; Baddeley, McNay, and Cassen, 2006; Nayyar 2008; Ghosh 2008; Ghosh 2010; Ghosh 2012; Kalra and Sodsriwiboon 2010). Some studies have also examined the club convergence hypothesis ${ }^{2}$ for Indian states and found limited support for it as well (Baddeley, McNay, and Cassen 2006; Bandyopadhyay 2011; Ghosh, Ghoshray, and Malki 2013).

Most studies that examine the convergence hypothesis in India are based on a cross-sectional growth convergence equation approach ${ }^{3}$ (Bajpai and Sachs 1999; Cashin \& Sahay, 1996b; Nagaraj, Varoudakis, and Veganzones 2000; Aiyar 2001; Trivedi 2002). Very few studies have followed a stochastic convergence approach. These latter studies have employed different techniques, such as stochastic kernel density in Bandyopadhyay (2011) or non-linear transition factor models in Ghosh, Ghoshray, and Malki (2013) and Phillips-Perron (PP) (Phillips 1987; Phillips and Perron 1988) unit root test without structural breaks in Ghosh (2012). None of these studies have used panel unit root tests with structural breaks. Many studies have highlighted the shortcoming of such time series approaches. Bandyopadhyay (2011), for example, pointed out that time series approaches that estimate the univariate dynamics of income remain incomplete when describing the dynamics of the entire cross section. Ghosh (2013) has argued that unit root tests employed in stochastic convergence literature are less reliable because they ignore possible structural breaks. Addressing these concerns, this article employs the latest advances in the time series approach to examine the stochastic income convergence hypothesis ${ }^{4}$ among 17 Indian states for the period 1960-2012. This article finds evidence to support income convergence among Indian states, contrary to earlier studies.

This article contributes to the literature on income convergence in India in several ways. First, the testing methodology used herein is not prone to rejections of the null hypothesis in the presence of a unit root with break(s). With this approach, the rejection of the null hypothesis (of a unit root) unambiguously implies stationarity in contrast to earlier uses of unit root tests with breaks, in which rejection of the null may indicate a unit root with break(s) rather than a stationary series with break(s). Second, this study employs panel versions of unit root tests with structural breaks that can exploit both the cross-sectional and time series information available in the data to evaluate the convergence hypothesis, while still allowing for potential structural breaks. Thus, in a situation in which univariate unit root tests (with or without structural breaks) give conflicting results, overall income convergence can still be ascertained. Third, cross-sectional dependence is a potential problem in examining the income convergence hypothesis for states within the same country. For example, cross-sectional dependence may arise due to the presence of economy-wide shocks, which can affect all regions simultaneously. One way to remove cross-sectional dependence is to use relative per capita income per state (i.e. the per capita income of a particular state divided by the average per capita income of a nation). This type of transformation has been used in various previous studies as well to account for

\footnotetext{
${ }^{2} \mathrm{Club}$ convergence entails identifying subsets of states that share the same steady state (or clustering the income data into convergence clubs) and checking whether convergence holds up within these groups (Ghosh, Ghoshray, and Malki 2013). In club convergence models, one state is a leading state, known as the leader. All countries with an initial income gap less than a particular amount (refer to Chatterjee (1992) for details) will eventually catch up with the leader. In the steady state, all these countries will grow at the same rate and constitute an exclusive convergence club.

${ }^{3}$ For details of this approach, refer to Barro and Sala-i-Martin (1992), Barro and Martin (1995)), Sala-i-Martin (1996) and Mankiw, Romer, and Weil (1992).

${ }^{4}$ The notion of stochastic convergence implies that shocks to the income of a country (or a region within a country) relative to the average income of a group of countries (or regions) will be temporary. This entails testing the null hypothesis of a unit root in the log of the ratio of per capita income relative to the average. Failure to reject the null of the unit root suggests incomes are diverging and provides evidence against income convergence. Alternatively, rejection of the null hypothesis of the unit root supports income convergence. Since the test includes a constant term, stochastic convergence implies that incomes converge to a country- or region-specific compensating differential. Hence, stochastic convergence is consistent with conditional convergence (Strazicich, Lee, and Day 2004).
} 
cross-sectional dependence in similar or different contexts (Bandyopadhyay 2011; Meng, Payne, and Lee 2013; Strazicich and List 2003; Strazicich, Lee, and Day 2004; Mishra and Smyth 2014). This transformation has the advantage of removing possible cross-sectional shocks that could have affected all states in the panel. For example, a positive shock to per capita state domestic product (SDP) across all states will increase the average by the same proportion and hence leave the relative per capita GDP series unchanged. This suggests that any structural breaks identified in the transformed series should be state specific. However, this relative measure of per capita income is not sufficient to remove cross-sectional dependence. Cross-sectional dependence along with the existence of structural breaks in the panel of states used in this study suggest that the income convergence hypothesis cannot be assessed unless a method is used that simultaneously takes into account these factors. Therefore, Bai and Carrion-i-Silvestre (2009) applied a panel unit root test that can address both possible cross-sectional dependence and structural breaks in a unified framework.

The rest of the article is organized as follows. Section II outlines the econometric methodology. Sections III and IV describe the data and present the results. Section V discusses the results, and Section VI presents the conclusions.

\section{Econometric methodology}

\section{Conventional unit root tests}

To start with, this article employs conventional univariate unit root testing methods without structural breaks as a benchmark. The comparison between these tests and tests with structural breaks helps to identify the extent to which misspecification is due to ignoring structural breaks. ${ }^{5}$

The augmented Dickey-Fuller test (ADF) (Dickey and Fuller 1979), the Kwiatkowski-PhillipsSchmidt-Shin (KPSS) stationarity test (Kwiatkowski et al. 1992) and the Lagrange multiplier (LM) unit root test proposed by Schmidt and Phillips (1992) were employed in this study. The null hypothesis for the ADF and LM unit root tests is that the per capita income series of state $i$ contains a unit root. If the null of a unit root is accepted for the per capita income series of state $i$, this implies that shocks to the relative income of state $i$ will be permanent. Hence, the per capita income of state $i$ will diverge from national per capita income. If the null hypothesis of a unit root is rejected, this suggests that shocks to the relative income of state $i$ will be temporary and that, over the long term, the per capita income of state $i$ will converge to the national average. The KPSS test differs from these two tests in its null hypothesis, in which the null hypothesis is indicated by stationarity trend, for example, against the alternative of a unit root. As these tests are well documented in the literature, they are not further discussed. ${ }^{6}$

\section{Cross-sectional dependence}

Another issue relevant for this analysis is cross-sectional dependence. As the states lie within a single monetary and fiscal regime and have a high degree of economic and cultural commonalities, their per capita incomes may exhibit cross-sectional dependence. This can create large distortions in univariate and panel unit root tests (Mishra, Sharma, and Smyth 2009). Transforming the series to the natural logarithm of the relative per capita series can remove cross-sectional dependence to an extent.

To test the effectiveness of the transformation to relative per capita income series in removing crosssectional dependence, Pesaran's (2004) cross-sectional dependence (CD) test was conducted before and after transforming income series into relative income series. The null hypothesis in the CD test is that the series are cross-sectionally independent. However, if cross-sectional dependence is found to be present in the data, Pesaran (2004) proposes a

\footnotetext{
${ }^{5}$ All the regression models employed in this article have both a constant term and linear time trend. With the inclusion of time trend in regression models, the notion of convergence can be interpreted as 'catching up' (definition 1, p. 165 Bernard and Durlauf's (1996)). As Bernard and Durlauf's (1996) pointed out that time-series tests for economies in a transition state (as is the case here) may erroneously accept the null of 'no convergence' when one economy' per capita output (state in our case) is converging to the per capita output of an economy sitting at a unique steady state from far below. Alternatively stated, time series test may give spurious results if data for the economies in question are driven by transitional dynamics. The inclusion of intercept (or constant term) in time series testing will account for initial conditions ignoring the transitional part. Therefore, inclusion of both intercept and time trend in the testing procedure will take care of initial conditions as well as transitional dynamics respectively improving the power of the time series tests.

${ }^{6}$ For details, refer to Smyth, Nielsen, and Mishra (2009).
} 
cross-sectionally dependent unit root test and its panel counterpart (CIPS), which specifically takes cross-sectional dependence into account. The null hypothesis of the CIPS test is the unit root, after accounting for cross-sectional dependence in the data.

\section{Univariate unit root tests with two structural breaks}

Another problem is the possibility of structural breaks in the data series. Many significant events occurred in the Indian economy during the 19602012 period, giving rise to the possibility of breaks in the trend rate of growth of per capita incomes, and ignoring this possibility could lead to erroneous results.

The LM unit root test of Lee and Strazicich (2003) and the KPSS unit root test of Carrion-i-Silvestre and Sansó (2007) with two endogenous breaks are applied in this study. In the ADF-type endogenous break unit root tests (Zivot and Andrews 1992; Lumsdaine and Papell 1997), the critical values are derived assuming no break(s) under the null hypothesis; therefore, it is possible to conclude that a data series is trend stationary when in reality it is nonstationary with breaks. This can give rise to a spurious rejection problem (Lee and Strazicich 2003). The LM unit root test, on the contrary, is unaffected by breaks under the null hypothesis of a unit root. This article applies the Model CC specification of Lee and Strazicich (2003) of the LM unit root test which can accommodate two breaks in the intercept and the slope. ${ }^{7}$ This test relies on determining the breaks where the endogenous two-break LM $t$-test statistic is at a minimum.

The other univariate unit root test used in this article is the KPSS stationarity test of Carrion-iSilvestre and Sansó (2007) with two endogenous breaks in the intercept and trend. This test has the null hypothesis of stationarity with structural breaks. For this test, this study used the Bartlett kernel and selected the bandwidth using Andrew's method. ${ }^{8}$ The break dates are estimated by minimizing the sequence of the sum of squared residuals (SSR) proposed by Kurozumi (2002). This procedure chooses the dates of the breaks from the argument that minimizes the sequence of $\operatorname{SSR}\left(T B_{1}, T B_{2}\right)$, where the SSR is obtained from the regression of $y_{t}=f\left(t, T B_{1}, T B_{2}\right)+e_{t}$, such that $f\left(t, T B_{1}, T B_{2}\right)$ denotes the determining specification.

\section{Panel unit root tests with structural breaks}

This article implements the panel KPSS stationarity test with multiple breaks (Carrion-i-Silvestre, BarrioCastro, and Lopez-Bazo 2005). This test has the null of stationarity. It allows the most general specification in which each state's relative per capita series can be modelled independently with its own structural breaks caused by state-specific shocks. In addition to the panel test statistic, this test also produces results for individual time series in the panel and allows different series to have a different number of structural breaks. Another salient feature of this test is that it only produces statistically significant breaks. To estimate the break dates, Lluis Carrioni-Silvestre, Barrio-Castro, and Lopez-Bazo (2005) applied the Bai and Perron (1998) technique. Trimming is necessary when computing estimates of break dates. The trimming region used here is $T[0.1,0.9]$. Once all possible dates are identified, Lluis Carrion-i-Silvestre, Barrio-Castro, and LopezBazo (2005) recommend that the optimal break dates be selected using the modified Schwartz information criterion (SIC) (Liu, Wu, and Zidek 1997) for trending regressors. This method involves sequential computation and the detection of breaks using a pseudo F-type test statistic. The Lluis Carrion-iSilvestre, Barrio-Castro, and Lopez-Bazo (2005) test allows for a maximum of five structural breaks.

The article also computes panel LM unit root tests with structural breaks (Im, Lee, and Tieslau 2005) as a robustness check. Unlike the Lluis Carrion-iSilvestre, Barrio-Castro, and Lopez-Bazo (2005) test, this test has the null hypothesis of panel unit root.

Finally, to include possible cross-sectional dependence and structural breaks in a unified framework, the Bai and Carrion-i-Silvestre (2009) panel unit root test is conducted. This article models the cross-sectional dependence as a common factors

\footnotetext{
${ }^{7}$ For other versions and more technical details of the test, refer to Smyth, Nielsen, and Mishra (2009).

${ }^{8}$ While the results as reported in this article use the Bartlett kernel, they were also estimated using the quadratic kernel. The results were not sensitive to the choice of kernel.
} 
model (e.g. Bai and Ng 2004; Moon and Perron 2004). These common factors can distinguish between the co-movements and idiosyncratic shocks that may affect individual time series. Once the time series are filtered for co-movements, the cross-sectional correlation is sufficiently reduced, and one can expect to derive valid panel data statistics.

The Bai and Carrion-i-Silvestre (2009) panel unit root test allows the common factors to be a nonstationary $I(1)$ process, a stationary $I(0)$ process or a combination of both. The advantage of this approach is that it allows common shocks to have different impacts on individuals via heterogeneous factor loadings. As the number and location of structural breaks are unknown and the common and idiosyncratic factors are typically unobservable, this article uses an iterative estimation procedure for handling the heterogeneous break points in the determining components.

The algorithm of this iterative procedure is detailed in Bai and Carrion-i-Silvestre (2009). After estimating the location of breaks, common factors, factor loadings and the magnitude of changes, modified Sargan-Bhargava (MSB) statistics are calculated for each series. Finally, the individual MSB statistics are pooled to construct the panel MSB. Based on the method used for pooling the individual statistics, Bai and Carrion-i-Silvestre (2009) suggest two types of panel MSB statistics: standardized statistics or a combination of $P$-values. As suggested in their article, standardized statistics are best suited for our purposes. Although this article proposes a relatively complicated model with both cross-sectional dependence and structural breaks modelled simultaneously in one framework, this model is closest to the empirical settings of the current article.

\section{Data}

The data used are the per capita net state domestic product (NSDP) for 17 major Indian states for the period from 1960 to 2012. Data were collected from the Indiastat database. The NSDPs for the 17 major states were expressed in Indian Rupees (INRs) and provided at different base periods. All the series were converted to the common base period of 20042005. ${ }^{9}$ The 17 major states included in our analysis account for roughly $90 \%$ of India's population and make up around $87 \%$ of India's GDP. ${ }^{10}$ The remaining 11 states not included in the analysis were either created very late in the period of analysis (such as Chhattisgarh, Jharkhand and Uttrakhand), were too small and had many missing data points (Goa, Mizoram, Sikkim, Arunachal Pradesh, Meghalaya and Himachal Pradesh, for example) or had unreliable data points (Jammu, Kashmir and Nagaland, for example). It is a common practise in studies containing state-level analyses of India to only focus on the 15-17 major states (refer to Table 3.1 in Ghosh 2013).

In the sample of states used in this article, nine states have average annual per capita income below INR 10,000 (US\$227), ${ }^{11}$ with Bihar at the bottom of the list. Three states (Haryana, Maharashtra and Punjab) have average annual per capita income above INR 15,000 (US\$ 341), and the remaining five states have average annual per capita income between INR 10,000-15,000 over the entire sample period. Haryana displays the highest fluctuations in income, as measured by standard deviation, and Bihar the lowest. ${ }^{12}$ These descriptive statistics are reported in Table 1.

This article has taken the relative per capita income measure to examine the convergence hypothesis. For this, the NSDP per capita of state $i$ is converted to its relative NSDP per capita, as follows:

$$
\begin{aligned}
& \text { Relative Per Capita } \mathrm{NSDP}_{i t} \\
& \quad=\ln \left(\frac{\text { PerCapita NSDP }_{i t}}{\text { National Per Capita Income }_{t}}\right)
\end{aligned}
$$

Panel B of Table 1 presents the descriptive statistics of the relative series of per capita income of state $\mathrm{i} /$ national per capita income. In a hypothetical scenario, where the per capita income of a state is exactly equal to the national per capita income, this series will take a value of one, whereas a value smaller than one would mean that the per capita income of that state is less than the

\footnotetext{
${ }^{9}$ The latest base period used for compiling the net state domestic products.

${ }^{10}$ The Republic of India, as of writing this article, is made up of 29 states and 6 union territories. However, one state (Telangana) was carved out of Andhra Pradesh in 2014. As the period of analysis for this study concludes in 2012, Telangana is not treated independently but is viewed as part of Andhra Pradesh.

${ }^{11}$ The average annual exchange rate between the Indian rupee and the US dollar during 2004-05 was 1 US\$ = 44 INR.

${ }^{12}$ The associated descriptive statistics table is given in the working paper version of this manuscript.
} 
Table 1. Descriptive statistics of per capita income for the sample period (1960-2012) for 17 major Indian states.

\begin{tabular}{|c|c|c|c|c|c|c|}
\hline Series & Observations & Mean & Std. Dev. & Min. & Max. & Skewness \\
\hline \multicolumn{7}{|c|}{ Panel A: SDP per capita (in Indian Rupees) } \\
\hline Andhra Pradesh & 53 & 12552 & 19108 & 316 & 78958 & 2.01 \\
\hline Assam & 53 & 7959 & 9959 & 395 & 40475 & 1.65 \\
\hline Bihar & 53 & 4449 & 5864 & 245 & 27202 & 2.14 \\
\hline Gujarat & 53 & 16166 & 24096 & 436 & 104261 & 2.06 \\
\hline Haryana & 53 & 18807 & 28490 & 382 & 119158 & 2.05 \\
\hline Karnataka & 53 & 13120 & 18853 & 373 & 76578 & 1.85 \\
\hline Kerala & 53 & 14801 & 21496 & 373 & 88527 & 1.86 \\
\hline Madhya Pradesh & 53 & 8036 & 10325 & 338 & 44989 & 1.80 \\
\hline Maharashtra & 53 & 17821 & 25621 & 463 & 103991 & 1.86 \\
\hline Manipur & 53 & 8261 & 9726 & 204 & 36937 & 1.31 \\
\hline Orissa & 53 & 8438 & 11883 & 275 & 49241 & 1.89 \\
\hline Punjab & 53 & 16518 & 21454 & 407 & 84526 & 1.62 \\
\hline Rajasthan & 53 & 9812 & 13606 & 388 & 59097 & 2.01 \\
\hline Tamil Nadu & 53 & 15464 & 23571 & 430 & 98628 & 2.05 \\
\hline Tripura & 53 & 10568 & 14780 & 369 & 60963 & 1.79 \\
\hline Uttar Pradesh & 53 & 6604 & 8193 & 307 & 33616 & 1.65 \\
\hline West Bengal & 53 & 10714 & 14659 & 452 & 61352 & 1.83 \\
\hline \multicolumn{7}{|c|}{ Panel B: SDP per capita as a fraction of National GDP per capita = SDP per capita in state $i /$ National GDP per capita } \\
\hline Andhra Pradesh & 53 & 0.94 & 0.11 & 0.78 & 1.16 & 0.60 \\
\hline Assam & 53 & 0.83 & 0.14 & 0.59 & 1.08 & -0.10 \\
\hline Bihar & 53 & 0.51 & 0.12 & 0.30 & 0.72 & -0.34 \\
\hline Gujarat & 53 & 1.28 & 0.12 & 1.04 & 1.54 & -0.04 \\
\hline Haryana & 53 & 1.42 & 0.20 & 0.95 & 1.77 & -0.67 \\
\hline Karnataka & 53 & 1.07 & 0.06 & 0.95 & 1.18 & 0.05 \\
\hline Kerala & 53 & 1.15 & 0.12 & 0.92 & 1.34 & 0.00 \\
\hline Madhya Pradesh & 53 & 0.81 & 0.11 & 0.58 & 0.97 & -0.65 \\
\hline Maharashtra & 53 & 1.39 & 0.17 & 1.10 & 1.68 & -0.18 \\
\hline Manipur & 53 & 0.83 & 0.17 & 0.52 & 1.14 & -0.38 \\
\hline Orissa & 53 & 0.76 & 0.07 & 0.64 & 0.91 & 0.14 \\
\hline Punjab & 53 & 1.50 & 0.19 & 1.08 & 1.81 & -0.59 \\
\hline Rajasthan & 53 & 0.92 & 0.10 & 0.73 & 1.14 & 0.06 \\
\hline Tamil Nadu & 53 & 1.13 & 0.17 & 0.87 & 1.45 & 0.26 \\
\hline Tripura & 53 & 0.94 & 0.09 & 0.69 & 1.10 & -0.77 \\
\hline Uttar Pradesh & 53 & 0.71 & 0.12 & 0.49 & 0.90 & -0.66 \\
\hline West Bengal & 53 & 1.01 & 0.10 & 0.86 & 1.20 & 0.13 \\
\hline
\end{tabular}

Values in bold indicate per capita income of the state is higher than national per capita income.

national average. A value greater than one would indicate that the per capita income of the state is higher than national per capita income. We note that the per capita income of the poorer states, such as Bihar, Uttar Pradesh and Orissa, are much lower than one, whereas some of the rich states, such as Haryana, Punjab, Gujarat and Maharashtra, are much higher than one.

The entire analysis was conducted on the natural logarithm of this transformed series. The natural logarithm of this relative series means that in the hypothetical scenario where a state's per capita income is exactly equal to the national per capita income, it would take a value of zero. If relative per capita NSDP is found to be stationary, this implies that the per capita income of the state is not drifting away from the national average in the long run. Any state-specific shocks (such as natural disasters, political turmoil or civil unrest) have only a temporary effect, and the per capita series eventually reverts to the national average. If most or all of the per capita income series are found to be stationary around the national average, this would support the income convergence hypothesis, whereas finding a unit root (or non-stationarity) would provide evidence against the convergence hypothesis for Indian states over the long term. This interpretation of convergence is consistent with existing studies that have adopted a time series approach for studying convergence. Some of these studies include Evans and Karras (1996), Evans (1998), Meng, Payne, and Lee (2013) and Mishra and Smyth (2014).

Figure 1 presents the time series plot of the natural logarithm of the relative NSDP series for each state. The horizontal line at zero indicates the hypothetical scenario in which state per capita income is the same as national per capita income (i.e. perfect convergence). A primary examination of the transformed series reveals that each state can be grouped into three distinct categories: states that stayed above the national average throughout the sample period (rich states), states that stayed below the national average (poor states) and states that moved above and below the national average (swing states). The first category 


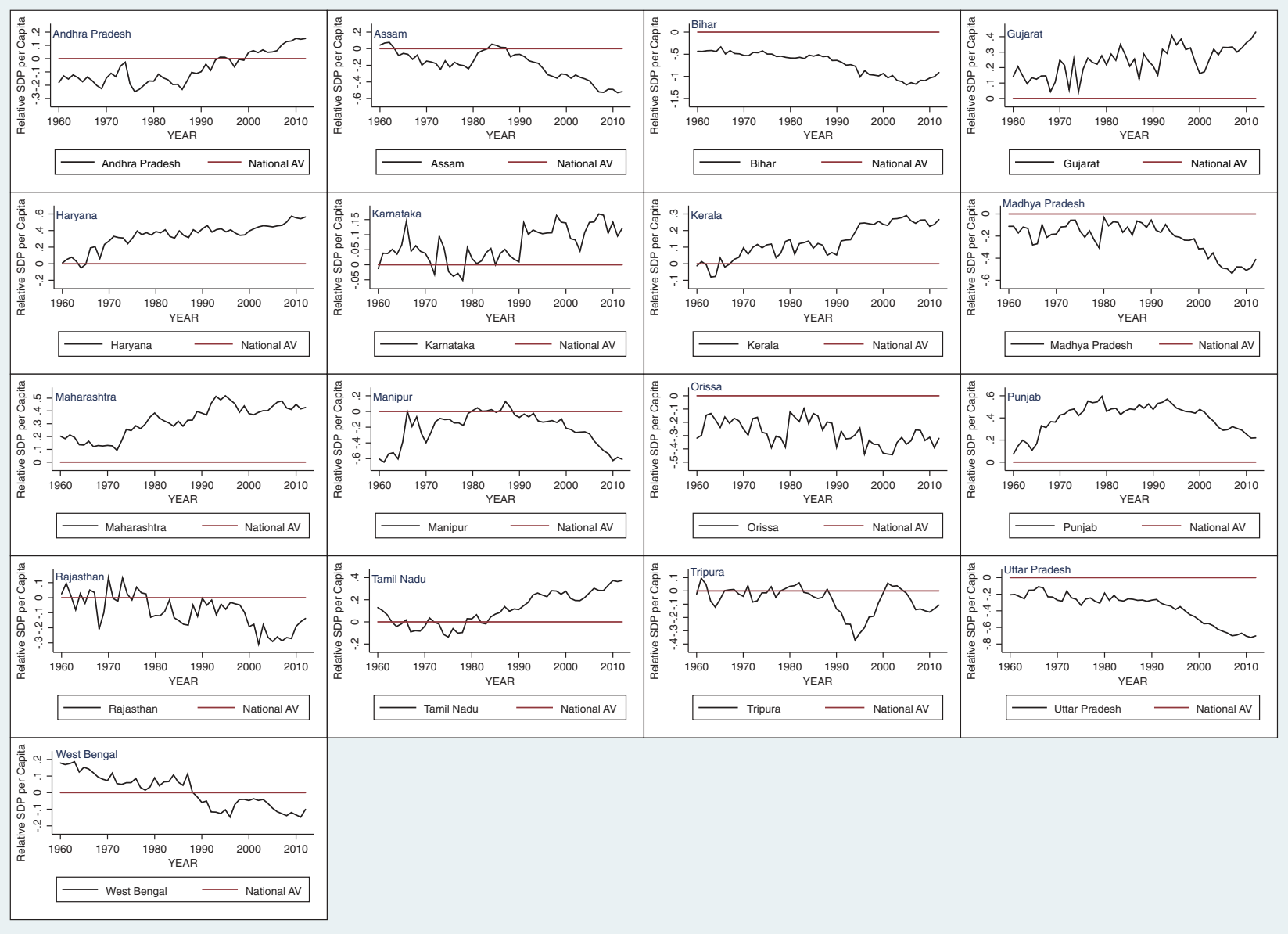

Figure 1. Graphs of relative SDP per capita compared to the national per capita GDP.

comprises Gujarat, Maharashtra and Punjab. The states of Haryana and Kerala are below the national average at the beginning of the sample. However, fairly early in the analysis period, their income surpasses the national average and remains above average for the rest of the analysis period. The second category comprises Uttar Pradesh, Bihar, Orissa and Madhya Pradesh. These states remain below the national average throughout the analysis period. The rest of the states (eight in total) also fall into the category of swing states.

\section{Results}

As a benchmarking exercise, the ADF, the Schmidt and Phillips LM unit root test and the KPSS stationarity test without structural breaks were carried out, and results are reported in Table 2. The results for the ADF test suggest that the null of unit root cannot be rejected in any of the transformed series at the traditional levels of significance. In the KPSS test, the null of stationarity is rejected for 11 out of 17 series. The Schmidt and Phillips LM test fails to reject the null of unit root in 12 out of 17 cases. On the basis of the univariate unit root tests without structural breaks, one can conclude that between zero and six states are converging towards national average per capita income.

The results for the test of cross-sectional independence are reported in Table 3. The top panel reports the results for the untransformed series. The Pesaran CD statistic is highly significant at all four lags, implying clear rejection of the null of cross-sectional independence. The bottom panel reports CD statistics for the transformed series, wherein the null hypothesis of cross-sectional independence is still rejected. Thus, transforming the series is not enough to remove the cross-sectional dependence in the sample, and there is a need to conduct a CIPS unit root test, which specifically takes into account cross-sectional dependence. 
Table 2. Traditional unit root tests without structural breaks.

\begin{tabular}{lcll}
\hline Series & $\begin{array}{c}\text { ADF } \\
\text { test }\end{array}$ & $\begin{array}{c}\text { KPSS } \\
\text { test }\end{array}$ & $\begin{array}{c}\text { Schmidt and Philips LM unit root } \\
\text { test }\end{array}$ \\
\hline $\begin{array}{l}\text { Andhra } \\
\text { Pradesh }\end{array}$ & -0.632 & $0.218^{* * *}$ & -2.491 \\
Assam & -0.631 & $0.161^{* *}$ & -1.553 \\
Bihar & -0.663 & $0.158^{* *}$ & -1.525 \\
Gujarat & -1.689 & 0.057 & $-5.096^{* * *}$ \\
Haryana & -1.703 & $0.160^{* *}$ & -1.740 \\
Karnataka & -2.228 & $0.143^{*}$ & $-4.088^{* * *}$ \\
Kerala & -1.160 & 0.062 & $-3.209^{* *}$ \\
Madhya & -1.045 & $0.213^{* *}$ & -2.027 \\
$\quad$ Pradesh & & & \\
Maharashtra & -1.194 & $0.121^{*}$ & -2.064 \\
Manipur & -1.821 & $0.250^{* * *}$ & -1.211 \\
Orissa & -2.440 & 0.072 & -2.253 \\
Punjab & -1.801 & $0.235^{* * *}$ & -0.878 \\
Rajasthan & -2.454 & 0.066 & $-3.911^{* * *}$ \\
Tamil Nadu & -0.409 & $0.160^{* *}$ & -1.321 \\
Tripura & -2.564 & 0.065 & -2.796 \\
Uttar Pradesh & -0.478 & $0.224^{* * *}$ & -1.019 \\
West Bengal & -1.361 & 0.051 & $-4.312^{* * *}$ \\
\hline
\end{tabular}

Sample consisted of annual data for the period 1960-2012. The unit root tests were preformed on the series.

$$
y_{i t}=\ln \left(\frac{\text { SDP Per Capita }}{i t} \text { Average SDP Per Capita }_{t}\right)
$$

with the assumption of an intercept and trend in the series. The lag lengths were selected using the Bayesian Information criteria (BIC). The null hypothesis for ADF and LM test is a unit root, whereas the null hypothesis for the KPSS test is stationarity. The maximum lag length was 10 based on the formula LagLength $=\operatorname{int}\left(12\left(\frac{T}{100}\right)^{0.25}\right)$ suggested by Hayashi $(2000,594)$. The critical values for each test are as follows:

$*^{*},{ }^{*}$ and ${ }^{* *}$ denotes statistical significance at the $10 \%, 5 \%$ and $1 \%$ levels respectively.

\begin{tabular}{lccc}
\hline & \multicolumn{3}{c}{ Critical values } \\
\cline { 2 - 4 } Test & $1 \%$ & $5 \%$ & $10 \%$ \\
\hline ADF & -3.58 & -2.93 & -2.60 \\
KPSS & 0.216 & 0.146 & 0.119 \\
Schmidt and Philips & -3.73 & -3.11 & -2.80 \\
\hline
\end{tabular}

Table 3. Cross-section correlation of the errors in the ADF( $p)$ regression for SDP per capita for the 17 major Indian states.

\begin{tabular}{|c|c|c|c|c|}
\hline & $P=1$ & $P=2$ & $P=3$ & $P=4$ \\
\hline \multicolumn{5}{|c|}{ Panel A = Actual SDP per capita } \\
\hline$\overline{\hat{\rho}}$ & 0.300 & 0.233 & 0.228 & 0.234 \\
\hline CD & $24.53^{* * *}$ & $19.03^{* * *}$ & $18.65^{* * *}$ & $19.08^{* * *}$ \\
\hline
\end{tabular}

Panel B = Relative SDP per capita [In(SDP per capita in state i/ National GDP per capita)]

$\begin{array}{lllll}\overline{\hat{\rho}} & 0.047 & 0.052 & 0.051 & 0.053 \\ \mathrm{CD} & 3.839^{* * *} & 4.209^{* * *} & 4.156^{* * *} & 4.365^{* * *}\end{array}$

The cross-sectional dependence (CD) test statistic is proposed in Pesaran (2004) for testing for cross-sectional dependence in panels. All statistics are based on univariate $\operatorname{AR}(p)$ specifications in the level of the variables with $p \leq 4$. The null hypothesis is that output innovations are crosssectionally independent. The $10 \%, 5 \%$ and $1 \%$ critical values for the CD statistic are 1.64, 1.96 and 2.57 , respectively.

$\overline{\hat{\rho}}$ is the simple average of the pair-wise cross-sectional coefficients of the individual $\operatorname{ADF}(p)$ regressions for lag lengths $-(p)=1,2,3$ and 4 .

*** denotes statistical significance at $1 \%$ level.
Table 4. CIPS test statistics (adjusting for cross-sectional dependence) for individual states.

\begin{tabular}{|c|c|c|c|c|}
\hline & $P=1$ & $P=2$ & $P=3$ & $P=4$ \\
\hline \multicolumn{5}{|c|}{$\begin{array}{l}\text { Relative SDP per capita [In(SDP per capita in state i/National GDP } \\
\text { per capita)] }\end{array}$} \\
\hline Andhra Pradesh & -2.51 & $-3.43^{*}$ & -2.95 & -2.99 \\
\hline Assam & $-3.63^{*}$ & -3.01 & -2.75 & -2.90 \\
\hline Bihar & -2.11 & -0.09 & -0.65 & -1.02 \\
\hline Gujarat & $-5.48 * * *$ & -3.41 & -3.30 & $-3.48^{*}$ \\
\hline Haryana & -3.40 & -3.02 & -2.20 & -1.93 \\
\hline Karnataka & $-3.70^{*}$ & -2.60 & -2.26 & -1.91 \\
\hline Kerala & $-3.68^{*}$ & -2.54 & -2.02 & -2.15 \\
\hline Madhya Pradesh & $-6.80^{* * *}$ & $-4.87^{* * *}$ & -2.98 & -2.93 \\
\hline Maharashtra & -2.92 & -3.04 & -2.99 & -3.35 \\
\hline Manipur & $-3.91^{* *}$ & -3.24 & -2.76 & -3.16 \\
\hline Orissa & $-4.28^{* *}$ & -2.92 & -2.35 & -2.97 \\
\hline Punjab & -2.12 & -1.99 & -1.93 & -2.02 \\
\hline Rajasthan & $-4.28^{* *}$ & -3.14 & -2.45 & -2.57 \\
\hline Tamil Nadu & $-3.50^{*}$ & -3.12 & -2.93 & -2.96 \\
\hline Tripura & -1.98 & -2.32 & -2.96 & -3.14 \\
\hline Uttar Pradesh & $-4.24^{* *}$ & -3.14 & -3.09 & -3.09 \\
\hline West Bengal & -3.06 & -2.28 & -2.26 & -2.51 \\
\hline
\end{tabular}

The null hypothesis is that the series has a unit root. The test was performed under the assumption there is an intercept and linear trend in the series (case 3 in Pesaran 2004). The 10\%, 5\% and 1\% critical values for case 3 with $\mathrm{T}=50, \mathrm{~N}=20$ from Pesaran (2004) are $-3.44,-3.79$ and -4.52 , respectively. ${ }^{*},{ }^{* *}$ and ${ }^{* * *}$ denotes statistical significance at the $10 \%, 5 \%$ and $1 \%$ levels, respectively.

The results of the Pesaran (2004) CIPS unit root test are reported in Table 4. The results of individual CIPS unit root tests suggest a failure to reject the null of unit root for most states. We note that the null of unit root is rejected at the 5\% level or lower for 6 states at lag 1, for only 2 states at lag 2 and for none at lags 3 and 4 . The results are similar to those obtained using the traditional unit root test: between zero and six states seem to be converging towards national average per capita income. Even though the CIPS test accounts for cross-sectional dependence, these results raise the possibility of a remaining specification bias due to unaccounted structural breaks.

Table 5 presents the LM unit root test results and the results of the KPSS stationarity test with two endogenous breaks. The Lee and Strazicich (2003) LM unit root test is an LM test with a null hypothesis of unit root in the series. Model CC, the most general specification of the test, was used. In this test, the null hypothesis of a unit root was rejected by looking at the LM parameter. The presence of significant structural breaks was determined by examining the significance of the dummies for breaks in intercept and trend. Table 5 reports the LM test statistics and the break dates, as identified by the test. In terms of the significance of the break dates, the results suggest that, in most of cases, both the dummies (break in intercept and break in trend) 
Table 5. KPSS and LM unit root tests with two structural breaks.

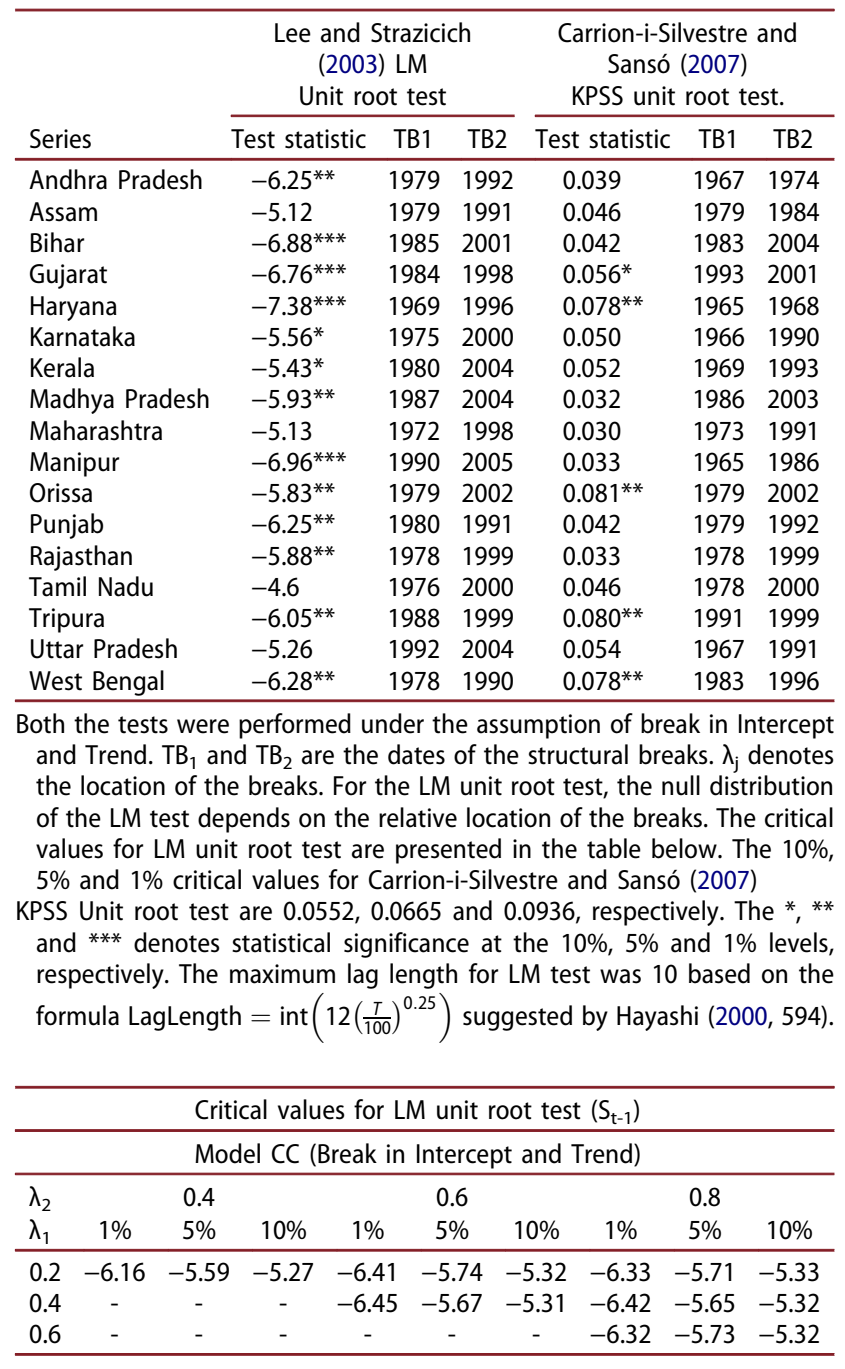

were significant or that at least one dummy was significant at each reported break date. After taking into account the occurrence of structural breaks in the series, the null of a unit root in the relative per capita NSDP series was rejected for 11 states $(64.8 \%$ of the sample) at the $5 \%$ level of significance or lower and for 13 states ( $76.5 \%$ of the sample) at the $10 \%$ level or higher. Comparing these results with those reported in Column 3 of Table 2, the number of states for which the null of unit root can be rejected increases dramatically when structural breaks were excluded from the data (for 13 out of 17 states in comparison with 5 out of 17).

The second test is the Carrion-i-Silvestre and Sanso (2007) KPSS test with two structural breaks, which has a null hypothesis of stationarity. This test uses the Bayesian information criterion (BIC) to select the two significant breaks over the entire set of break-point combinations. The results of this test can be compared with the KPSS test results reported in Table 1, Column 2. The KPSS test uses the same methodology but does not allow for structural breaks in the data. The KPSS test with structural breaks fails to reject the null hypothesis of stationarity for 13 states $(76.5 \%$ of the sample) at the $5 \%$ level and for 12 states $(70.5 \%$ of the sample) at the $10 \%$ level or higher.

The results of individual states for the Lluis Carrion-i-Silvestre, Barrio-Castro, and Lopez-Bazo (2005) KPSS unit root test are reported in Table 6. This test was conducted allowing a maximum of five structural breaks in the intercept and trend of each state's series. However, not every state had five significant structural breaks in the relative per capita NSDP series. Table 6 reports only the significant structural breaks. Even after accounting for up to five structural breaks, the null of stationarity is still found to be rejected in five out of seventeen states.

In the next step, the stationarity of the overall panel was assessed. Table 7 reports the panel unit root test results for the Hadri (2000) test (without structural breaks), the Lluis Carrion-i-Silvestre, Barrio-Castro, and Lopez-Bazo (2005) test (with a maximum of five structural breaks), the Im, Lee, and Tieslau (2005) LM unit root test (with zero, one and two structural breaks) and the Pesaran (2004) CIPS test. The Hadri (2000) and Lluis Carrion-i-Silvestre,

Table 6. Results for the individual states of the panel KPSS test with multiple structural breaks.

\begin{tabular}{lcccccc}
\hline Series & $\begin{array}{c}\text { KPSS test statistic } \\
\text { (Bartlett kernel) }\end{array}$ & $\mathrm{TB}_{1}$ & $\mathrm{~TB}_{2}$ & $\mathrm{~TB}_{3}$ & $\mathrm{~TB}_{4}$ & $\mathrm{~TB}_{5}$ \\
\hline Andhra Pradesh & $0.112^{* * *}$ & 1967 & 1974 & 1980 & 1986 & 1995 \\
Assam & $0.075^{* *}$ & 1973 & 1979 & 1984 & 1995 & 2005 \\
Bihar & 0.038 & 1983 & 1994 & 2004 & - & - \\
Gujarat & 0.044 & 1998 & - & - & - & - \\
Haryana & 0.032 & 1965 & 1968 & 1996 & - & - \\
Karnataka & 0.018 & 1965 & 1972 & 1978 & 1990 & - \\
Kerala & 0.049 & 1964 & 1976 & 1980 & 1987 & 1994 \\
Madhya Pradesh & 0.057 & 1964 & 1974 & 1979 & 1986 & 2003 \\
Maharashtra & 0.023 & 1972 & 1981 & 1991 & 1997 & - \\
Manipur & $0.182^{* * *}$ & 1965 & 1970 & 1988 & 2005 & - \\
Orissa & 0.029 & 1961 & 1979 & 2002 & - & - \\
Punjab & $0.142^{* * *}$ & 1965 & 1979 & 1992 & - & - \\
Rajasthan & 0.032 & 1967 & 1970 & 1978 & 1999 & - \\
Tamil Nadu & 0.038 & 1969 & 1973 & 2000 & - & - \\
Tripura & 0.044 & 1962 & 1982 & 1987 & 1993 & 2000 \\
Uttar Pradesh & $0.098^{* *}$ & 1967 & 1971 & 1975 & 1990 & 2007 \\
West Bengal & 0.028 & 1979 & 1987 & 1996 & - & - \\
\hline
\end{tabular}

** and ${ }^{* * *}$ denote significance at the $5 \%$ and $1 \%$ levels, respectively. Significance is determined using Bootstrap critical values based on a Monte Carlo simulation with 20,000 replications proposed by Maddala and Wu (1999). The procedure for calculating Bootstrap critical values is summarized in Appendix 1. The test was performed allowing for a maximum of five breaks in Intercept and Trend. 
Table 7. Results of panel unit root tests.

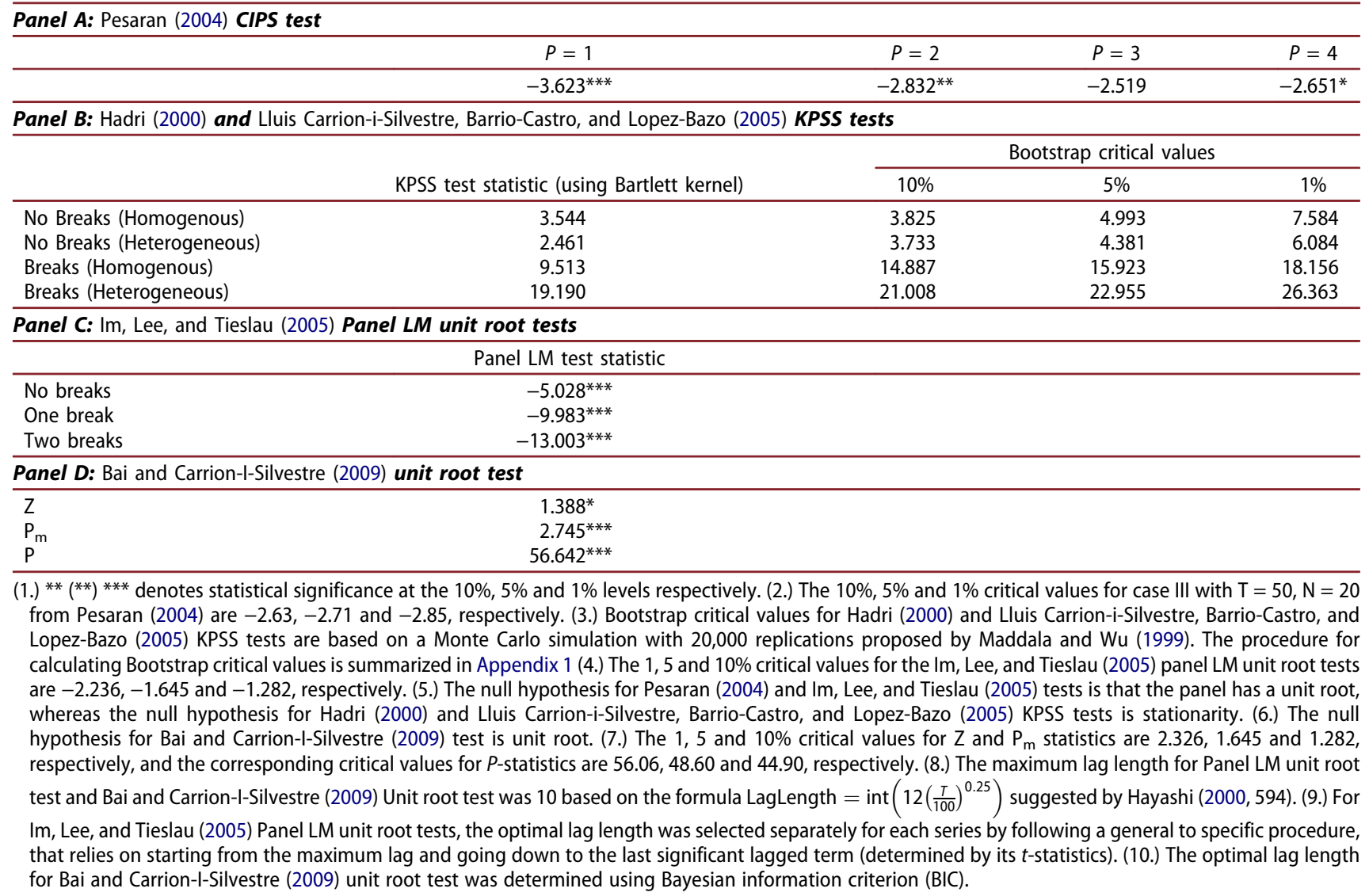

Barrio-Castro, and Lopez-Bazo (2005) tests are reported with two alternative assumptions: namely, that the long-term variance was homogeneous or was heterogeneous. The null hypothesis of stationarity was not rejected in any of the cases. This result is robust with regards to the alternative assumptions about the variance and the presence/number of structural breaks in the data. These results were confirmed by the panel LM unit root test (Im, Lee, and Tieslau 2005), reported in Panel C of Table 7. The null hypothesis in this case is a unit root; the test was conducted with alternate specifications of zero, one and two structural breaks in the individual data series. The null hypothesis of unit root was rejected at traditional levels of significance in all the specifications. The results of the Pesaran (2004) CIPS tests remain inconclusive with regards to the convergence hypothesis at the overall panel level. The null hypothesis of a unit root was rejected for lags 1 and 2 but was accepted for the lags 3 and 4 at a $5 \%$ level of significance.

An overall view of the results obtained so far suggests the tests with structural breaks (that ignore cross-sectional dependence) show evidence for convergence, whereas the tests that account for crosssectional dependence (but ignore structural breaks) fail to find evidence in support of convergence. To resolve this apparent contradiction, the Bai and Carrion-I-Silvestre (2009) test was used, which simultaneously takes into account possible cross-sectional dependence and multiple endogenous structural breaks. Panel D of Table 7 reports the results of the Bai and Carrion-i-Silvestre (2009) test for the overall panel. All three test statistics reject the null of unit root, suggesting income convergence among Indian states, after controlling for both cross-sectional dependence and structural breaks.

\section{Discussion}

The results of this study are discussed along two lines. First, evidence for and against income convergence among Indian states is considered. Second, the dates of the structural breaks identified by the tests are addressed in addition to whether these dates 
actually correspond with major events affecting the Indian economy.

\section{Evidence for convergence}

The results of the unit root tests without structural breaks suggest that out of 17 states, anywhere between zero to six states are converging towards the national average, while the rest are diverging. These results are in line with the findings of Ghosh (2013) and Bandyopadhyay \& Lusksic (2015) who applied unit root tests without structural breaks to examine stochastic convergence. ${ }^{13}$ Ghosh (2013) found convergence for five states while Bandyopadhyay \& Lusksic (2015) found four states to be converging in their sample of 15 states. As previously noted, standard unit root tests are less reliable and have low power due to structural breaks that are unaccounted for in the series. Therefore, in allowing for the possibility of structural breaks in the series, we found greater evidence in favour convergence. The same unit root tests (i.e. KPSS and LM tests) give a non-stationary result for most of the series when structural breaks are not included (Table 3) and detect stationarity (for most of the series) when two structural breaks are taken into account (Table 5). The states which do not conform to the convergence hypothesis also vary depending on the unit root test used. The fact that the stationarity hypothesis is rejected for a few states in each test is probably due to the way a particular test models the data generating process.

The results for the individual states in the panel KPSS test (as reported in Table 6) were expected to suffer the least from any possible misspecification bias in the structural breaks, as the possibility of ignoring structural breaks is minimized by allowing five breaks. If anything, there is a possibility of overfitting the data by allowing too many structural breaks, which would bias the results in favour of convergence. However, this test does not provide stronger evidence for the convergence hypothesis than the tests with two structural breaks and suggests that five states are not converging towards the national average.
In summary, three tests of stationarity that do not allow for structural breaks in the series (ADF test, KPSS test and Schmidt and Phillips unit root test; presented in Table 2) and three tests that allow for structural breaks (Lee and Strazicich 2003; LM unit root test, Carrion-i-Silvestre and Sansó 2007; KPSS unit root test and results for individual states following the Lluis Carrion-i-Silvestre, Barrio-Castro, and Lopez-Bazo 2005 panel unit root test; presented in Tables 5 and 6) were applied. The following rule of thumb was used to assess the overall results for each category: 'If two out of three tests in a particular category suggest stationarity, the series should be categorized as stationary. Otherwise, it is nonstationary'.

Based on this rule of thumb, all states except for Gujarat, Kerala, Rajasthan and West Bengal are nonstationary when structural breaks are not allowed, whereas only the states of Assam and Uttar Pradesh are found to be non-stationary when two or more structural breaks are allowed in the series. To decide between the conflicting stationarity and non-stationarity results, the results obtained from the model with structural breaks are taken as the final result. Tests that allow for structural breaks assumed more parameters in the data generating process and hence better fit the data. Also, given the time series of the last five decades, it seemed natural to rely on the model with structural breaks. Using this decision rule, only the states of Assam and Uttar Pradesh are found to be non-stationary, that is, do not conform to the convergence hypothesis.

The different versions of the panel unit root tests suggest convergence in per capita incomes. In particular, the results suggest that majority of the states (11-13 in a panel of 17 states) are stochastically converging despite strong differences in the per capita incomes of states. We looked at several other studies to seek potential reasons behind this finding that would support convergence for Indian states. Bandyopadhyay \& Lusksic (2015) found that shocks to the relative incomes are not permanent for the majority of Indian states and that states exhibit a tendency of mean reversion. This holds true even for the very poor states for which the effect of shock dissipates for the majority of them within 10 years.

\footnotetext{
${ }^{13}$ The study by Ghosh (2013) uses Phillips-Perron (PP) unit root test and Bandyopadhyay \& Lusksic (2015) apply ADF, DF-GLS and KPSS tests without structural breaks.
} 
Ghosh (2013) noted that inter-state variation in physical and social infrastructure has declined though marginally over the years. This can be one of the possible reasons of ensuing convergence for Indian states, as a large number of studies in the literature have found strong links between infrastructure and economic development of the region (such as Bandyopadhyay 2011; Ghosh 2013). Besides, the Finance Commission and Planning Commission took several steps to promote regional equality through the intergovernmental transfer of resources (for details, refer to Ghosh (2013)).

\section{Structural breaks}

The presence of structural breaks has significant implications for our findings. As pointed out by Strazicich, Lee, and Day (2004), state-specific conditioning variables, such as physical infrastructure/ investment expenditure (as measured by irrigation, electrification and railway track-building expenditure in Bandyopadhyay 2011; or Baddeley, McNay, and Cassen 2006), or social infrastructure (defined as human capital in Lahiri and Yi 2009) can be permanently altered following a major shock, making permanent changes to the time path of relative income. In next few paragraphs, the probable causes of these structural breaks are explored. However, these causes can only be considered as probable events relating to breaks and not as evidence of a statistical association with these proposed events or with the time periods of structural breaks. To establish any causal relationship between political, economic and environmental events and a statistically significant break in income is beyond the scope of present study but would be interesting to explore in further research.

For the majority of states, with the exception of Bihar, Gujarat and Tripura, the first and second structural breaks in relative income occurred during the period from 1966 to 1979. India experienced three economic crises during the period, one in 1965-1966, a second in 1973-1974 and a third in 1979-1980 (the period when a second structural break was encountered in most states). All three crises were predominantly balance-of-payment crises caused by a shortage of food crops, which were triggered by droughts and further aggravated by external factors such as wars (with Pakistan in 1965 and 1971) and the international oil crises of 1973 and 1979.

Many states experienced a structural break in the mid to late 1980s. These include Andhra Pradesh (1986), Assam (1984), Bihar (1983-1984), Gujarat (1984), Kerala, Madhya Pradesh, Manipur, Tripura and West-Bengal in the 1985-1987 period. This period was also marked by several significant political and economic incidents in India. The Indian economy witnessed a turnaround and experienced high growth in the 1980s. This period of development was also characterized by an unsustainable level of government spending, resulting in mounting internal and external debt, that along with expenditure on subsidies gave rise to a severe balance-of-payments crisis in India in 1991. On the sociopolitical front as well, many dramatic changes occurred that may have had varying levels of instantaneous or delayed impact on different states. In 1984, after the assassination of the then Prime Minister, Indira Gandhi, communal riots broke out in New Delhi and in most of northern India, which led to the massacre of around 5000 citizens of the Sikh faith in Delhi, Kanpur, and other cities. The same year, 1984, also witnessed the world's worst industrial disaster in terms of human lives affected. On 3 December 1984, in Bhopal, the capital city of the central state of Madhya Pradesh, a chemicals manufacturing company (Union Carbide Corporation) released methyl isocyanate (MIC) into the atmosphere above Bhopal. The leak was due to employer negligence and poor plant maintenance. Officially, the state government placed the death toll at around 4000; however, unofficial estimates have calculated that 20,000 people were killed and over 500,000 injured. The insurgency in the state of Jammu and Kashmir (not included in this analysis) took a difficult turn in 1989 with the exodus of the Kashmiri Pandits (members of a minority Hindu community in the Kashmir valley) and the targeted killing of key community figures. In a relatively short space of time, close to 75,000 Kashmiri Pandit families were forced to flee Kashmir and to seek refuge in other north Indian states. This had considerable impact on the resources and sociopolitical dynamics of many neighbouring states.

With the exception of Haryana, Madhya Pradesh, Orissa and Tamil Nadu, all states experienced a structural break at some point between 1991 and 
1995. Balance-of-payments problems, which started in 1985, continued to be experienced throughout the 1990s. The Iraqi invasion of Kuwait in August 1990 resulted in a sharp increase in the international price of oil, further aggravating the problem, and, by the end of 1990, the Indian economy witnessed a very acute macroeconomic crisis. The government was close to default. The central bank had been refused new credit, and foreign exchange reserves had been reduced to such a point that India could barely finance 3 weeks' worth of imports. After securing a loan of US\$ 2.2 billion from the IMF (pledging 67 tons of India's gold reserves as collateral), the Indian government initiated a major programme of structural and economic reforms in 1991, bringing about significant policy changes in the external, financial and industrial sectors.

On the political front, ex-prime minister Rajiv Gandhi was assassinated in May 1991 by the Liberation Tigers of Tamil Elam (LTTE), a militant organization from Sri Lanka. The Indian economy experienced a period of political uncertainty from 1996 to 1999, with three general elections in 3 years. India also faced a brief period of war with Pakistan in 1999, known as the Kargil War, and short-lived economic sanctions by the United States as a fall out from nuclear tests in 1998.

In addition to the national events described above, many state-specific events/developments took place during the evaluated period. These can be used to explain the existence of structural breaks in the income series of a particular state that do not match any national event. Table 8 lists the statespecific events that occurred around the break dates.

\section{Case study of Uttar Pradesh and Assam}

As noted earlier, for two states, Uttar Pradesh and Assam, convergence to the national average did not hold true in the majority of the tests. A critical analysis of the events in these states is conducted at following in order to discover the reasons behind non-convergence in these states.
Panel B of Figure 2 depicts the breaks in the relative per capita series for Uttar Pradesh. The first structural break in the series seems to be corresponding with the economic crisis of 1965-1966 or the India-Pakistan war of 1965 . The second structural break, which occurs in either 1971 or 1975 , seems to broadly correspond with either the third India-Pakistan war of 1971 or the state of emergency declared by Indira Gandhi's government ${ }^{14}$ in 1975 . However, the reasons for the third structural break in Uttar Pradesh (1990-1991) correspond with factors internal to the state rather than national ones. The average per capita income in India increased around 5.5 times in the 16year period between 1991 and 2007 but for Uttar Pradesh increased only 3.5 times. In relative per capita income terms, Uttar Pradesh became poorer compared with the rest of India, as the relative per capita SDP of Uttar Pradesh has fallen from $77 \%$ in 1991 to $50 \%$ of national per capita SDP in 2007.

The most probable causes for this decline are the political uncertainty and religious unrest prevailing in Uttar Pradesh. In the 16-year period, beginning with the government led by Mualayam Singh in December 1989 through the start of the government led by Mayawati in May 2007, the state witnessed 14 changes of government (accompanied by extended periods of presidential rule), with no chief minister completing his/her full term. There was also religious unrest, and several communal riots broke out during the period. The demolition of a disputed mosque-like structure in Ayodhaya (a city in the Faizabad district of Uttar Pradesh) in 1992 led to the outbreak of HinduMuslim riots in Uttar Pradesh and in many other parts of India and resulted in an estimated death toll of more than 2000 people. Another structural break in Uttar Pradesh's data series occurred in 2007 (at the same time as the Mayawati government was elected and completed the full term). However, the post-2007 sample is too small to be conclusive about the trend in the relative per capita income series following that year.

Meanwhile, the relative per capita SDP of Assam and the estimated structural breaks are presented in Figure 2 (Panel A). Assam is situated in the northeastern region of India. Assam is rich in natural

\footnotetext{
${ }^{14}$ The central government, led by Indira Gandhi, ordered the arrest of more than 1000 key political opponents in 1975 and declared a state of emergency that curbed the power of the press, reduced civil liberties to minimum and suspended elections. The emergency lasted for a 21-month period from June 1975 to March 1977 during which most of Gandhi's political opponents were in prison. This period also witnessed other atrocities, most prominent of which was a forced mass-sterilization campaign spearheaded by Sanjay Gandhi, the Prime Minister's son. The Emergency is one of the most controversial periods of independent India's history.
} 
Table 8. Major events in states around the break dates.

\begin{tabular}{|c|c|c|}
\hline Series & Break dates & Major events around the break dates \\
\hline $\begin{array}{l}\text { Andhra } \\
\text { Pradesh }\end{array}$ & $\begin{array}{l}\text { 1967, 1974, 1979, } 1980 \\
\text { 1986, 1992, } 1995\end{array}$ & $\begin{array}{l}\text { 1969: Political crisis due to Telangana agitation } \\
\text { 1972: Political crisis due to 'Jai Andhra' movement } \\
\text { 1983-1984: regime change as TDP (Telugu Desam party), established by N.T. Ramarao (NTR), came to } \\
\text { power and Congress Party lost election first time after independence. } \\
\text { NTR regime (1983-1989) was the period of rapid economic growth due to educational reforms, local } \\
\text { government empowerment, irrigation and electricity improvements and corruption controls measures. } \\
\text { 1989: 'IT (Information Technology) revolution' mainly in Hyderabad }\end{array}$ \\
\hline Assam & $\begin{array}{l}1973,1979,1984,1991 \\
\quad 1995,2005\end{array}$ & $\begin{array}{l}\text { 1979: Beginning of 'Assam movement' against undocumented immigrants } \\
\text { 1985: Assam movement ended following 'Assam accord' } \\
\text { 1990: president rule was imposed due to deteriorating law and order situation because of indirect } \\
\text { support of AGP (Asom Gana Parishad) to ULFA (United Liberation Front of Assam) terrorist activities. } \\
\text { Subsequently, military was deployed and ULFA was banned. } \\
\text { 2005: Attack on oil pipelines by a terrorist organization ULFA }\end{array}$ \\
\hline Bihar & $\begin{array}{l}\text { 1983, 1985, 1994, } \\
2001,2004\end{array}$ & $\begin{array}{l}\text { 1984: Anti-Sikh riots in northern India including Bihar following the assassination of Indira Gandhi } \\
\text { 1990-2005: characterized as Lalu Prasad/Rabri Devi era (Rashtriya Janata Dal (RJD) Party) marked by } \\
\text { complete collapse of economy, excessive rise in crimes and mass migration to other states } \\
\text { 2000: divided into two states; Bihar (northern part) and Jharkhand (southern part and more industrialized } \\
\text { region) } \\
\text { 2005: Change in political regime as Nitish Kumar (Janata Dal (United) became CM }\end{array}$ \\
\hline Gujarat & 1984, 1993, 1998, 2001 & $\begin{array}{l}\text { 1981, 85: Anti-reservation agitation } \\
\text { 1994: breaking out of plague epidemic predominantly in Surat resulted in mass migration } \\
\text { 1998: severe tropical cyclone hit several districts in coastal areas of Gujarat and Rajasthan. } \\
\text { 2001: Massive earthquake leading to huge loss of lives and property }\end{array}$ \\
\hline Haryana & 1965, 1968, 1969, 1996 & $\begin{array}{l}\text { 1966: came into existence as separate administrative entity, was the part of Punjab before } \\
\text { 1996: change in political regime from Congress party to HVP (Haryana Vikas Party), a breakaway party } \\
\text { from Congress, which merged again into Congress party in } 1994\end{array}$ \\
\hline Karnataka & $\begin{array}{l}1965,1966,1972,1975 \\
1978,1990,2000\end{array}$ & $\begin{array}{l}\text { 1962-1968: development of various agricultural, irrigation, industrial and transport projects like } \\
\text { 'Sharavathi Hydroelectric Project' and 'Cauvery Basin Irrigation Project.' } \\
\text { 1974: Enactment of 'New land Reform Act' which abolished all forms of tenancies and made tenants } \\
\text { owner of the land they cultivated. One major drawback of this reform was provision of 'land ceilings' } \\
\text { which increased the proportion of small and marginal farmers and adversely affect the agriculture. } \\
\text { 1980s: the emergence of Karnataka as IT capital of India. This took major upturn in early 1990s due to STPI } \\
\text { (Software Technology Parks of India) scheme (1988-1991) and trade liberalization policies in early 1990s. } \\
\text { 1997: Karnataka became the first state to announce State IT policy }\end{array}$ \\
\hline Kerala & $\begin{array}{l}\text { 1964, 1969, 1976, 1980, 1987, } \\
\text { 1993, 1994, } 2004\end{array}$ & $\begin{array}{l}\text { 1970: Land reform Act which ended the feudal system and ensured rights of tenants on land came into } \\
\text { force. Before that few other land reforms bills were passed in 1960, 1963, } 1964 \text { and } 1969 \text {. } \\
\text { 1976,79, } 89 \text { and 1992: broad gauge railway lines connecting various cities became operational. } \\
\text { 2004: the Indian ocean tsunami caused heavy damage and loss of life to coastal villages of Kerala }\end{array}$ \\
\hline $\begin{array}{l}\text { Madhya } \\
\text { Pradesh }\end{array}$ & $\begin{array}{l}1964,1974,1979,1986 \\
1987,2003,2004\end{array}$ & $\begin{array}{l}\text { 1984:Bhopal Gas tragedy, world's worst industrial disaster } \\
\text { 2000: Formation of Chhattisgarh, a separate state, from Madhya Pradesh }\end{array}$ \\
\hline Maharashtra & $\begin{array}{l}\text { 1972, 1973, 1981, 1991, } \\
\text { 1997, } 1998\end{array}$ & $\begin{array}{l}\text { 1972: Drought in Maharashtra } \\
\text { 1993: Latur Earthquake } \\
\text { 1992-1993: Mumbai riots followed by Mumbai bombings } \\
\text { 2000: Introduction of 'special economic zones' to create a transparent system and procedure for } \\
\text { enhancing productivity and ease of doing business }\end{array}$ \\
\hline Orissa & 1961, 1979, 2002 & $\begin{array}{l}\text { 1962: Balimela Reservoir Project was started } \\
\text { 1964: HAL (Hindustan Aeronautics Limited) plan was set up. } \\
\text { 1981: NALCO (National Aluminium Company Limited), one of Asia's largest integrated aluminium } \\
\text { complex was founded with a headquarter in Bhubaneswar. } \\
\text { 1999: A major cyclone hit Orissa causing huge economic damage and loss of human lives. }\end{array}$ \\
\hline Punjab & $\begin{array}{l}\text { 1965, 1979, 1980, 1991, } \\
1991\end{array}$ & $\begin{array}{l}\text { 1965: start of green revolution (application of high yielding variety of seeds which double the production } \\
\text { of wheat and rice manifolds). } \\
\text { 1966: Punjab was split into three states: Punjab, Haryana and Himachal Pradesh } \\
\text { 1979-1984: insurgency period as Sikh militants demanded autonomy for Punjab and resorted to violence. } \\
\text { 1984: operation 'Blue Star' to combat Sikh insurgency } \\
\text { 1984: Anti-Sikh riots after the assassination of Indira Gandhi (prime minister) } \\
\text { 1992: Congress party came to power after } 5 \text { years (roughly) of president rule }\end{array}$ \\
\hline Rajasthan & 1967, 1970, 1978, 1999 & $\begin{array}{l}\text { 1967-1970: increase in the spending on education and health (above national average in 1970) } \\
\text { 1977-1980: period of political uncertainty before Congress Party came into power in June,1980 } \\
\text { 1998: Shift in political leadership from BJP to Congress Party }\end{array}$ \\
\hline Tamil Nadu & $\begin{array}{l}1969,1973,1976 \\
1978,2000\end{array}$ & $\begin{array}{l}\text { 1965: Anti Hindi agitation } \\
\text { 1967: Regime change as DMK (Dravida Munnetra Kazhagam) took control of the state, ending the } \\
\text { stronghold of Congress. } \\
\text { 1972: DMK was split and AIADMK (All India Anna Dravida Munnetra Kazhagam) was formed out of it, } \\
\text { 1977: AIADMK came to power defeating DMK } \\
\text { 1995-1996: setting up of manufacturing plant by global auto manufacturers like Hyundai, Ford and Mitsubishi } \\
\text { 1997: IT (information technology) policy paved the path for sustained growth of IT industry } \\
\text { 2004: Indian Ocean tsunami which severely affected the east coast of Tamil Nadu. }\end{array}$ \\
\hline $\begin{array}{l}\text { Uttar } \\
\text { Pradesh }\end{array}$ & $\begin{array}{l}\text { 1967, 1971, 1975, 1990, 1991, } \\
\text { 1993, 1999, } 2007\end{array}$ & $\begin{array}{l}\text { 1965: start of green revolution benefitted the western region } \\
\text { 1992: Demolition of Babri Masjid provoking violent riots later on } \\
\text { 2000: Uttarakhand was formed out of Uttar Pradesh } \\
\text { 2007: onset of Ms. Mayawati government, the first government to complete its full term after a period of } \\
\text { 16 years }\end{array}$ \\
\hline
\end{tabular}


Table 8. (Continued).

\begin{tabular}{lcc}
\multicolumn{1}{c}{ Break dates } & \\
\hline Weries & 1974: Smallpox epidemic & Major events around the break dates \\
& & 1977: Major shift in politics when CPI (M) (Communist Party of India (Marxist)) came to power, defeating \\
& Congress party, and governed the state till 2011. \\
& 1979: major drought & 2000: Change in leadership from Jyoti Basu (CM for 23 years) to Buddhadeb Bhatacharya \\
& &
\end{tabular}

The break dates in this table is a superset of all the significant structural breaks reported LM 2 breaks unit root test, KPSS 2 breaks stationarity test and KPSS Multiple break stationarity test.

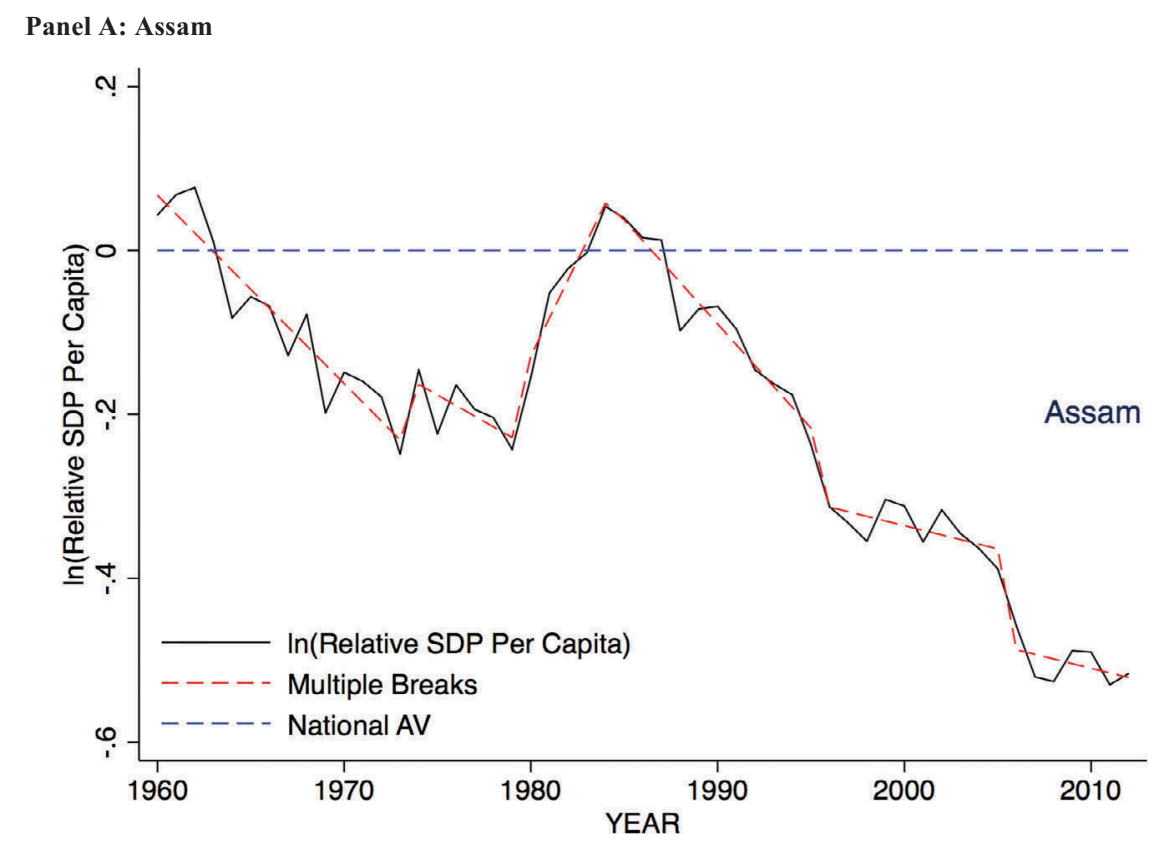

Panel B: Uttar Pradesh

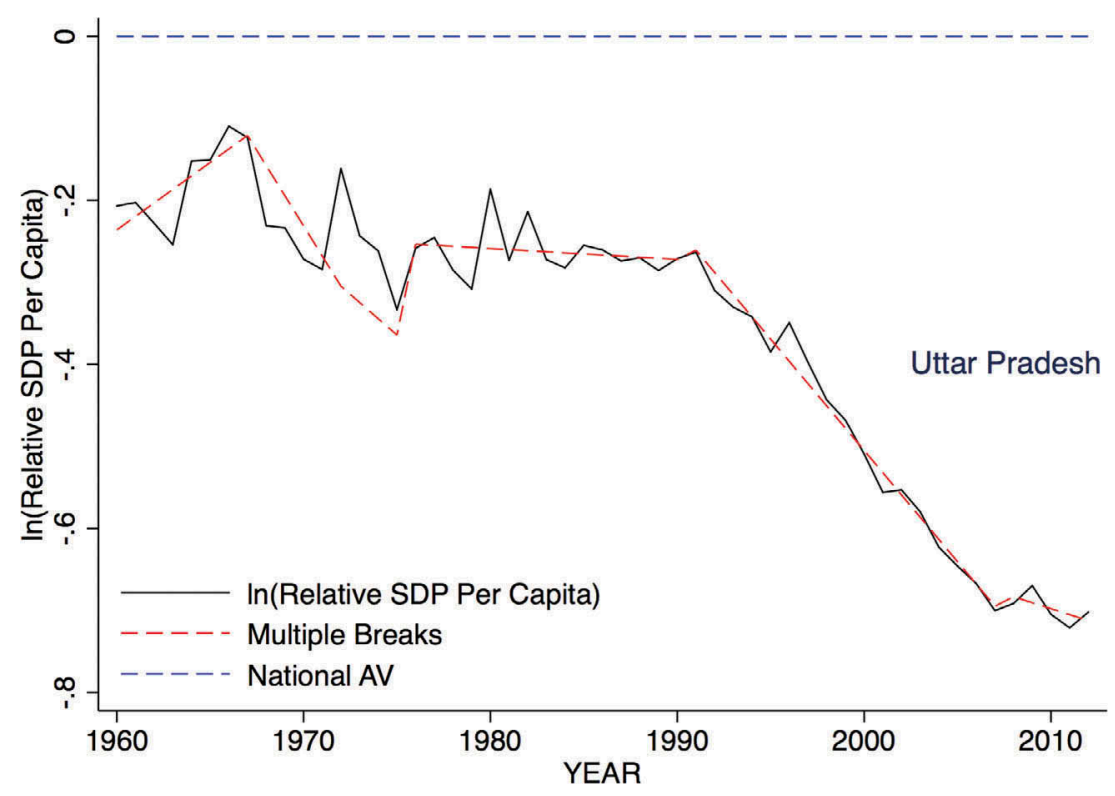

Figure 2. Multiple structural breaks in the relative SDP per capita of Uttar Pradesh and Assam.

resources and one of the largest tea-growing regions in the world. Although well-endowed with natural resources, Assam's growth rate has not kept pace with the rest of India. Assam started with per capita income above the national average in the 1960s and remained close to the national average until the first 
break in income, which occurred somewhere around the mid-to-late 1970s. The per capita income of Assam was 1.04 of the national average in 1960 yet had fallen to 0.78 of the national average in 1979. This corresponded with the period when the Assam Movement (1979) started to take action against undocumented immigrants. The period ended with the signing of the Assam Accord in 1985 when Asom Gana Parishad (AGP), the party formed by the leaders of the movement, came to power in the state. The second break in Assam's relative per capita income occurred at about this point. Some improvement in the growth rate of Assam's economy was observed during 1985-1990, with average per capita income rising marginally above the national average until the third break in relative per capita income, which took place in the early 1990s. Since this period, the relative per capita income of Assam continues to decline and be below the national average. The main reason for this is the deteriorating law and order situation as a result of indirect support given by the AGP to ULFA (United Liberation Front of Assam) terrorist activities. ULFA, formed in 1979, was the first major insurgent organization in Assam. Its influence on state politics gradually increased, leading to the collapse of the government in 1990. Presidential rule was imposed from November 1990 to June 1991. Subsequently, the army was deployed in Assam, and ULFA was banned by the Government of India. Militant activity still continues in the state. However, in recent years, the government is making some headway through counterinsurgency offensives and peace efforts. ${ }^{15}$

\section{Conclusion}

Using the latest advances in time series techniques, this article examines the conditional income convergence hypothesis for 17 Indian states from 1960 to 2012. Although the results suggest that unit root tests without structural breaks do not support the income convergence hypothesis for Indian states, tests that include structural breaks provide significant evidence in support of conditional income convergence. Since the panel of states exhibited cross-sectional dependence with respect to structural breaks, a testing procedure that simultaneously took these into account was employed. This test provided evidence in support of the conditional income convergence hypothesis for our panel of states. When considered individually, not all states included in the panel are found to be converging. Around 11-13 states (depending on the testing methodology) were found to share a common, steady path with the average national income.

\section{Acknowledgements}

We thank Prof. Russell Smyth (Monash university), participants of 10th Annual Conference on Economic Growth and Development (Indian Statistical Institute) and the two anonymous referees for helpful comments on earlier versions of this article. We thank Prof. Josep Lluís Carrion-i-Silvestre (University of Barcelona) for providing the GAUSS codes for estimating the unit root tests proposed in Carrion-i-Silvestre and Sansó (2007) and Bai and Carrion-i-Silvestre (2009). We, alone, are responsible for the views expressed therein and any remaining errors.

\section{Disclosure statement}

No potential conflict of interest was reported by the authors.

\section{ORCID}

Ankita Mishra (iD) http://orcid.org/0000-0002-4121-8749

Vinod Mishra (D) http://orcid.org/0000-0002-4686-5195

\section{References}

Aiyar, S. 2001. "Growth Theory and Convergence across Indian States: A Panel Study.” In T. Callen, P. Reynolds and C. Towe (eds) India at Crossroads: Sustaining Growth and Reducing Poverty, 143-169. Washington: International Monetary Fund.

Baddeley, M., K. McNay, and R. Cassen. 2006. "Divergence in India: Income Differentials at the State Level, 1970-97." The Journal of Development Studies 42 (6): 1000-1022. doi:10.1080/00220380600774814.

Bai, J., and J. L. Carrion-i-Silvestre. 2009. "Structural Changes, Common Stochastic Trends, and Unit Roots in Panel Data." Review of Economic Studies 76 (2): 471-501. doi:10.1111/j.1467-937X.2008.00530.x.

Bai, J., and P. Perron. 1998. "Estimating and Testing Linear Models with Multiple Structural Changes." Econometrica, $66: 47-78$

\footnotetext{
${ }^{15}$ For further details, refer to the report on the insurgency and peace efforts in Assam by the Centre for Development and Peace Studies (available at http:// cdpsindia.org/assam_insurgency.asp).
} 
Bai, J., and S. Ng. 2004. "A Panic Attack on Unit Roots and Cointegration.” Econometrica 72 (4): 1127-1177. doi:10.1111/j.1468-0262.2004.00528.x.

Bajpai, N., and J. D. Sachs. 1999. “The progress of policy reforms and variations in performance at the sub-national level in India (HIID Development Discussion Paper No. 730)". Cambridge, MA: Harvard Institute for International Development, Harvard University.

Bandyopadhyay, S. 2011. "Rich States, Poor States: Convergence and Polarisation in India." Scottish Journal of Political Economy 58 (3): 414-436. doi:10.1111/j.14679485.2011.00553.x.

Bandyopadhyay, S., and J. Luksic. 2015. "Spatial inequality and stochastic convergence in India: 1960-2011.” Paper presented at 6th ECINEQ Meeting, Université du Luxembourg, Campus Kirchberg, Luxembourg, July 13-15, 2015. Available online at: http://www.ecineq.org/ecineq_lux15/FILESx2015/CR2/p245. pdf [Date Accessed: 20 April 2017]

Barro, R., and S. Martin. 1995. Economic Growth. Boston, MA : The MIT Press.

Barro, R. J., and X. Sala-i-Martin. 1992. “Convergence.” Journal of Political Economy 100 (2): 223. doi:10.1086/261816.

Bernard, A. B., and S. N. Durlauf. 1995. "Convergence in International Output.” Journal of Applied Econometrics 10: 97-108. doi:10.1002/jae.3950100202.

Bernard, A. B., and S. N. Durlauf. 1996. "Interpreting Tests of the Convergence Hypothesis." Journal of Econometrics 71 (1-2): 161-173. doi:10.1016/0304-4076(94)01699-2.

Bhattacharya, B. B., and S. Sakthivel. 2004. "Regional Growth and Disparity in India: Comparison of Pre- and Post-Reform Decades." Economic and Political Weekly 39 (10): 1071-1077.

Carlino, G. A., and L. O. Mills. 1993. "Are U.S. Regional Incomes Converging?" Journal of Monetary Economics 32 (2): 335-346. doi:10.1016/0304-3932(93)90009-5.

Carrion-i-Silvestre, J. L., and A. Sansó. 2007. "The KPSS Test with Two Structural Breaks." Spanish Economic Review 9 (2): 105-127. doi:10.1007/s10108-006-9017-8.

Cashin, P., and R. Sahay. 1996a. "Internal Migration, CentreState Grants and Economic Growth in the States of India." IMF Staff Papers 43 (1): 123-171. doi:10.2307/3867355.

Cashin, P., and R. Sahay. 1996b. "Regional Economic Growth and Convergence in India." Finance and Development 33 (1): 49-52.

Chatterjee, M. 1992. "Convergence Clubs and Endogenous Growth.” Oxford Review of Economic Policy. 8 (4): 57-69. doi:10.1093/oxrep/8.4.57.

Dasgupta, D., P. Maiti, R. Mukherjee, S. Sarkar, and S. Chakrabarti. 2000. "Growth and Interstate Disparities in India." Economic and Political Weekly 35 (27): 2413-2422.

Dholakia, R. H. 1994. "Spatial Dimensions of Accelerations of Economic Growth in India." Economic and Political Weekly 29 (35): 2303-2309.

Dickey, D. A., and W. A. Fuller. 1979. "Distribution of the Estimators for Autoregressive Time Series with a Unit Root." Journal of the American Statistical Association 74: 427-431. doi:10.2307/2286348.
Evans, P. 1996. "Using Cross-Country Variances to Evaluate Growth Theories." Journal of Economic Dynamics and Control 20 (6-7): 1027-1049. doi:10.1016/0165-1889(95) 00888-8.

Evans, P. 1997. "How Fast Do Economics Converge?" Review of Economics and Statistics 79 (2): 219-225. doi:10.1162/ 003465397556809.

Evans, P. 1998. "Using Panel Data to Evaluate Growth Theories." International Economic Review 39 (2): 295305. doi:10.2307/2527294.

Evans, P., and G. Karras. 1996. "Convergence Revisited." Journal of Monetary Economics 37: 249-265. doi:10.1016/ S0304-3932(96)90036-7.

Fleissig, A., and J. Strauss. 2001. "Panel Unit-Root Tests of OECD Stochastic Convergence." Review of International Economics 9 (1): 153-162. doi:10.1111/roie.2001.9.issue-1.

Galor, O. 1996. "Convergence? Inferences from Theoretical Models." The Economic Journal. 106 (437): 1056-1069. doi:10.2307/2235378.

Ghosh, B., and P. De. 1998. "Role of Infrastructure in Regional Development: A Study of India over the Plan Period." Economic and Political Weekly 33 (47-48): 3039-3048.

Ghosh, M. 2008. "Economic Reforms, Growth and Regional Divergence in India." Margin: the Journal of Applied Economic Research 2 (3): 265-285. doi:10.1177/ 097380100800200303.

Ghosh, M. 2010. "Economic Policy Reforms and Regional Inequality in India." Journal of Income and Wealth 32 (2): 71-88.

Ghosh, M. 2012. "Regional Economic Growth and Inequality in India during the Pre- and Post-Reform Periods." Oxford Development Studies 40 (2): 190-212. doi:10.1080/ 13600818.2012.677818.

Ghosh, M. 2013. "Regional Economic Growth and Inequality." In Liberalization, Growth and Regional Disparities in India, India Studies in Business and Economics Series, 17-45. India: Springer. doi:10.1007/ 978-81-322-0981-2_3.

Ghosh, M., A. Ghoshray, and I. Malki. 2013. "Regional Divergence and Club Convergence in India." Economic Modelling 30: 733-742. doi:10.1016/j.econmod.2012.10.008.

Hadri, K. 2000. "Testing for Stationarity in Heterogeneous Panel Data." The Econometrics Journal 3 (2): 148-161. doi:10.1111/ectj.2000.3.issue-2.

Hayashi, F. 2000. Econometrics. Princeton: Princeton University Press.

Im, K., J. Lee, and M. Tieslau. 2005. "Panel LM Unit-Root Tests with Level Shifts." Oxford Bulletin of Economics and Statistics 67 (3): 393-419. doi:10.1111/obes.2005.67.issue-3.

Kalra, S., and S. Sodsriwiboon. 2010. "Growth Convergence and Spillovers among Indian States: What Matters? What Does Not?" (IMF Working Paper No. WP/10/96). Washington, DC: International Monetary Fund.

Kar, S., and S. Sakthivel. 2007. "Reforms and Regional Inequality in India." Economic and Political Weekly 42 (47): 69-77. 
Kurozumi, E. 2002. "Testing for Stationarity with a Break." Journal of Econometrics 108: 63-99. doi:10.1016/S03044076(01)00106-3.

Kwiatkowski, D., P. C. B. Phillips, P. Schmidt, and Y. Shin. 1992. "Testing the Null Hypothesis of Stationarity against the Alternative of a Unit Root: How Sure are We that Economic Time Series Have a Unit Root?" Journal of Econometrics 54 (1-3): 159-178. doi:10.1016/0304-4076 (92)90104-Y

Lahiri, A., and K.-M. Yi. 2009. "A Tale of Two States: Maharashtra and West Bengal." Review of Economic Dynamics 12 (3): 523-542. doi:10.1016/j.red.2008.09.006.

Lee, J., and M. C. Strazicich. 2003. "Minimum Lagrange Multiplier Unit Root Test with Two Structural Breaks." Review of Economics and Statistics 85 (4): 1082-1089. doi:10.1162/003465303772815961.

Li, H., and G. S. Maddala. 1996. "Bootstrapping Time Series Models (With Discussion).” Econometric Reviews 15: 115195.

Liu, J., S. Wu, and J. V. Zidek. 1997. "On Segmented Multivariate Regression.” Statistica Sinica 7 (2): 497-525.

Carrion-i-Silvestre, J. L., D. Barrio-Castro, and E. LopezBazo. 2005. "Breaking the Panels : An Application to the GDP per Capita." Econometrics Journal 8: 159-175. doi:10.1111/j.1368-423X.2005.00158.x.

Lumsdaine, R. L., and D. H. Papell. 1997. "Multiple Trend Breaks and the Unit-Root Hypothesis." Review of Economics and Statistics 79: 212-218. doi:10.1162/ 003465397556791.

Maddala, G. S., and S. Wu. 1999. "A Comparative Study of Unit Root Tests with Panel Data and A New Simple Test." Oxford Bulletin of Economics and Statistics Special Issue 61: 631-652. doi:10.1111/obes.1999.61.issue-S1.

Mankiw, N., D. Romer, and D. Weil. 1992. "A Contribution to the Empirics of Economic Growth." Quarterly Journal of Economics 107: 407-437. doi:10.2307/2118477.

Marjit, S., and S. Mitra. 1996. "Convergence in Regional Growth Rates: Indian Research Agenda." Economic and Political Weekly 31 (33): 2239-2242.

Meng, M., J. E. Payne, and J. Lee. 2013. "Convergence in per Capita Energy Use among OECD Countries." Energy Economics 36: 536-545. doi:10.1016/j.eneco.2012.11.002.

Mishra, V., and R. Smyth. 2014. "Convergence in Energy Consumption per Capita among ASEAN Countries." Energy Policy 73: 180-185. doi:10.1016/j. enpol.2014.06.006.
Mishra, V., S. Sharma, and R. Smyth. 2009. “Are Shocks to Real Output Permanent or Transitory? Evidence from a Panel of Pacific Island Countries." Pacific Economic Bulletin 24 (1): 65-82.

Moon, H. R., and B. Perron. 2004. "Testing for a Unit Root in Panels with Dynamic Factors.” Journal of Econometrics 122 (1): 81-126. doi:10.1016/j.jeconom.2003.10.020.

Nagaraj, R., A. Varoudakis, and M. A. Veganzones. 2000. "Long-Run Growth Trends and Convergence across Indian States." Journal of International Development 12: 45-70. doi:10.1002/(SICI)1099-1328(200001)12:1<45:: AID-JID586>3.0.CO;2-Z.

Nayyar, G. 2008. "Economic Growth and Regional Inequality in India." Economic and Political Weekly 43 (6): 58-67.

Pesaran, M. H. 2004. "General Diagnostic Tests for Cross Section Dependence in Panels." Cambridge Working Papers in Economics No. 435, University of Cambridge, and CESifo Working Paper Series No. 1229, Cambridge, UK.

Phillips, P. C. B. 1987. "Time Series Regression with Unit Roots." Econometrica 55 (2): 277-302. doi:10.2307/ 1913237.

Phillips, P. C. B., and P. Perron. 1988. "Testing for a Unit Root in Time Series Regression.” Biometrika 75 (2): 335 346. doi:10.1093/biomet/75.2.335.

Rao, M. G., R. T. Shand, and K. P. Kalirajan. 1999. "Convergence of Incomes across Indian States: A Divergent View." Economic and Political Weekly 34 (13): 769-778.

Sachs, J. D., N. Bajpai, and A. Ramiah. 2002. “Understanding regional economic growth in India (CID Working Paper No. 88)." Cambridge, MA: Centre for International Development, Harvard University

Sala-i-Martin, X. X. 1996. "The Classical Approach to Convergence Analysis.” The Economic Journal 106: 10191036. doi: $10.2307 / 2235375$.

Schmidt, P., and P. C. B. Phillips. 1992. "LM Tests for a Unit Root in the Presence of Deterministic Trends." Oxford Bulletin of Economics and Statistics 54 (3): 257-287. doi:10.1111/j.1468-0084.1992.tb00002.x.

Shetty, S. L. 2003. "Growth of SDP and Structural Changes in State Economies: Interstate Comparison." Economic and Political Weekly 38 (49): 5189-5200.

Smyth, R., I. Nielsen, and V. Mishra. 2009. “"I”Ve Been to Bali Too' (And I Will Be Going Back): Are Terrorist Shocks to Bali's Tourist Arrivals Permanent or 
Transitory?" Applied Economics 41 (11): 1367-1378. doi:10.1080/00036840601019356.

Strazicich, M. C., J. Lee, and E. Day. 2004. "Are Incomes Converging among OECD Countries? Time Series Evidence with Two Structural Breaks." Journal of Macroeconomics 26 (1): 131-145. doi:10.1016/j.jmacro.2002.11.001.

Strazicich, M. C., and J. A. List. 2003. "Are CO2 Emission Levels Converging among Industrial Countries?" Environmental and Resource Economics 24 (3): 263-271. doi:10.1023/A:1022910701857.

\section{Appendix 1}

Summary of Maddala and Wu (1999) Bootstrap procedure for calculating Critical values.

Maddala and Wu (1999) propose a bootstrap methodology to get the empirical distribution of the test statistics to make inferences that are not affected by cross-correlated errors in the data. The method proposed by Maddala and $\mathrm{Wu}$ (1999) extends the method proposed by Li and Maddala (1996) for univariate time series to a panel setting.

This methodology relies on generating a bootstrap sample $y^{*}=\alpha \beta_{0}+\epsilon^{*}$, such that $\epsilon^{*}$ in the bootstrap sample is taken from $\epsilon^{0}=y-\alpha \beta_{0}$ of original sample. In this case, as we are interested in a Panel data, the bootstrap sample of error terms $\epsilon^{0}$ would be from:

$$
\Delta y_{i t}=\eta_{i} \Delta y_{i t-1}+\epsilon_{i t}^{0}
$$

Trivedi, K. 2002. "Regional convergence and catch-up in India between 1960 and 1992 (Working Paper, No. 2003W01)." Oxford: Nuffield College, University of Oxford.

Young, A. T., M. J. Higgins, and E. U. S. C. Data. 2008. "Sigma Convergence versus Beta Convergence." Money, Credit and Banking 40: 5.

Zivot, E., and D. W. K. Andrews. 1992. "Further Evidence on the Great Crash, the Oil-Price Shock, and the Unit-Root Hypothesis." Journal of Business \& Economic Statistics 10. doi:10.1198/073500102753410372.

However, due to cross-correlations among $\epsilon_{i t}^{0}$, one cannot resample $\epsilon_{i t}^{0}$ directly. Maddala and $\mathrm{Wu}$ (1999) recommend resampling $\epsilon_{i t}^{0}$ with the cross-section index fixed i.e. picking up $\epsilon_{i t}^{0}$ from $\epsilon_{t}^{0}=\left[\epsilon_{1 t}^{0}, \epsilon_{2 t}^{0}, \ldots \ldots \epsilon_{N t}^{0}\right]$ to get $\epsilon_{t}^{*}$. This will ensure that the cross-correlation structure of the error terms is not altered due to resampling.

Following this technique, the bootstrap sample generated is:

$$
\begin{gathered}
y_{i t}^{*}=y_{i t-1}^{*}+u_{i t}^{*} \text { with } y_{i 0}^{*}=0 \\
u_{i t}^{*}=\hat{\eta}_{i} u_{i t-1}^{*}+\epsilon_{i t}^{*} \text { with } u_{i, 0}^{*}=\sum_{j=0}^{m} \hat{\eta}_{i}^{j} \epsilon_{-j}^{*}
\end{gathered}
$$

such that $\hat{\eta}_{i}$ 's are collected from regression in equation $(A 1)$ conducted over randomly selected bootstrap samples. We conducted the above set of estimations 20,000 times to generate the empirical distributions, which was subsequently used to generate the critical values. The estimations were carried out using the Gauss code provided by Prof. Josep Lluís Carrion-i-Silvestre. 